\title{
Resilient microorganisms in dust samples of crossank the International Space Station-survival of the adaptation specialists
}

\author{
Maximilian Mora ${ }^{1 \dagger}$, Alexandra Perras ${ }^{1,2+}$, Tatiana A. Alekhova ${ }^{3}$, Lisa Wink ${ }^{1}$, Robert Krause ${ }^{1}$, Alina Aleksandrova ${ }^{3}$, \\ Tatiana Novozhilova ${ }^{3}$ and Christine Moissl-Eichinger ${ }^{1,4^{*}}$
}

\begin{abstract}
Background: The International Space Station (ISS) represents a unique biotope for the human crew but also for introduced microorganisms. Microbes experience selective pressures such as microgravity, desiccation, poor nutrient-availability due to cleaning, and an increased radiation level. We hypothesized that the microbial community inside the ISS is modified by adapting to these stresses.

For this reason, we analyzed 8-12 years old dust samples from Russian ISS modules with major focus on the long-time surviving portion of the microbial community. We consequently assessed the cultivable microbiota of these samples in order to analyze their extremotolerant potential against desiccation, heat-shock, and clinically relevant antibiotics. In addition, we studied the bacterial and archaeal communities from the stored Russian dust samples via molecular methods (next-generation sequencing, NGS) and compared our new data with previously derived information from the US American ISS dust microbiome.

Results: We cultivated and identified in total 85 bacterial, non-pathogenic isolates (17 different species) and 1 fungal isolate from the 8-12 year old dust samples collected in the Russian segment of the ISS. Most of these isolates exhibited robust resistance against heat-shock and clinically relevant antibiotics. Microbial 16S rRNA gene and archaeal $16 \mathrm{~S}$ rRNA gene targeting Next Generation Sequencing showed signatures of human-associated microorganisms (Corynebacterium, Staphylococcus, Coprococcus etc.), but also specifically adapted extremotolerant microorganisms. Besides bacteria, the detection of archaeal signatures in higher abundance was striking.
\end{abstract}

Conclusions: Our findings reveal (i) the occurrence of living, hardy microorganisms in archived Russian ISS dust samples, (ii) a profound resistance capacity of ISS microorganisms against environmental stresses, and (iii) the presence of archaeal signatures on board. In addition, we found indications that the microbial community in the Russian segment dust samples was different to recently reported US American ISS microbiota.

Keywords: International Space Station, Microbiome, Confined habitat, Archaea, Extremotolerant

\section{Background}

The International Space Station (ISS) is a highly unusual working place. Completely sealed off from the outside, crews of three to ten astronauts and cosmonauts have routinely inhabited the modules since 2000 -as have billions of microorganisms. The ISS represents the most

\footnotetext{
* Correspondence: christine.moissl-eichinger@medunigraz.at

${ }^{\dagger}$ Equal contributors

'Department for Internal Medicine, Section of Infectious Diseases and Tropical Medicine, Medical University of Graz, Auenbruggerplatz 15, 8036 Graz, Austria

${ }^{4}$ BioTechMed Graz, Krenngasse 37, 8010 Graz, Austria

Full list of author information is available at the end of the article
}

confined, man-made inhabited environment to date, characterized by radiation levels higher than on Earth, low nutrient levels due to reduced introduction of organic material, constant temperature (approx. $22{ }^{\circ} \mathrm{C}$ ), stable humidity (approx. 60\%), and microgravity [1].

The majority of the microorganisms detected on board the ISS are human-associated (as reviewed in $[1,2]$ ) and the ISS microbiome thus resembles the microbiome of indoor environments on Earth [3]. Next to human-derived (opportunistic) pathogens [4, 5], also technophilic microorganisms, which are able to corrode 
spacecraft materials [6-9], potentially inhabit the interior of the ISS. Therefore, the ISS microbial community is under constant surveillance to ensure the health of the human crew working on-board, as well as to evaluate potential risk factors for the integrity of the ISS materials and its function.

NASA (National Aeronautics and Space Administration) has identified that knowledge of the ISS microbiome is a major target for ongoing and future research studies. There is particular interest on the response of microbial communities to selective pressures such as microgravity, which could induce severe changes and adaptation processes [10].

Recent studies assessed the ISS dust microbiota using next-generation sequencing (NGS) techniques [5] and compared the microbial diversity with ground control samples [4]. The authors confirmed the anticipated composition of the ISS microbiota, as representing a typical human-associated community [4]. This observation appears logical due to the tremendous impact of the human microbiota on the environment (e.g., the human body spreads $10^{6}$ bacteria per hour through breathing [11]) and the severe restriction of other potential microbe sources. The major bacterial phyla detected by NGS-based methods were Firmicutes, Actinobacteria, and Proteobacteria [4], with the dominant genera Corynebacterium and Propionibacterium, representing typical human skinassociated microorganisms [12]. Besides NGS, cultivationbased approaches were also applied, which resulted in a high number of Bacillus and Staphylococcus isolates [4].

Standardized monitoring of surface and air samples on board the ISS as well as more detailed post-flight investigations have been and are currently being conducted (e.g., NASA's Microbial Observatory Project). Another recent project, Merccuri (Microbial Ecology Research Combining Citizen and University Researchers on the ISS), studied 48 bacterial strains that were transferred from Earth environments to the ISS [3]. For most of the cultures, the researchers found no significant change with respect to growth rate during the few days incubation time, except for Bacillus safensis, which grew $60 \%$ better in space than on Earth [3]. However, selective pressures (desiccation, radiation, chemical, and physical stresses) on board the ISS could cause an adaptation of the indigenous microbiota towards ISS conditions during a longer time frame $[13,14]$.

The questions concerning a possible adaptation of microorganisms towards ISS stresses are addressed within an ESA flight project originally named "ARBEX" (Archaeal and Bacterial Extremophiles on board the ISS) now "Extremophiles" [2], which aims to analyze the adaptation processes of moderate and extremotolerant Bacteria and Archaea on the ISS. Thus far, Archaea have not been found in samples from the ISS [4] but have frequently been detected in human-associated environments and clean rooms [15], as they are integral part of the human skin and gut microbiota $[16,17]$ and can therefore also be expected on board the ISS.

The ARBEX project focuses on the hardiest microorganisms inhabiting the ISS and assessing their diversity and capabilities to resist certain stresses. For this study, we specifically selected dust samples from the Russian modules that were obtained 8-12 years ago and stored since then under dried and sealed conditions on Earth. Targeting long-time survivors and spore-forming microorganisms, we consequently assessed the cultivable microbial community of these samples, in order to obtain model microbial strains that could be utilized in analyzing specific adaptation towards environmental stresses, such as desiccation and lack of nutrients. We analyzed these microorganisms with respect to their resistance to thermal stress and clinically relevant antibiotics. In addition, we assessed the bacterial and archaeal communities from the stored dust samples via molecular methods (nextgeneration sequencing, NGS) and compared our new data with the previously derived information from the ISS microbiome [4].

\section{Methods \\ Origin of samples}

Extracts of different ISS samples obtained from the Russian Service Module of the ISS were provided by $\mathrm{T}$. Alekhova and her team. Dust samples were retrieved during ISS-expedition 9 in October 2004 and during ISS-expedition 16 in April 2008: sample 1: "Dust filter-1 (2004)," dust filter of ventilation system (internal abbreviation: RISS1); sample 2: "Dust filter-2 (2004)," dust filter of ventilation system (internal abbreviation: RISS4); sample 3: "Dust collector (2004)," from vacuum cleaner (internal abbreviation: RISS5); sample 4: "Dust filter (2008)," dust filter of ventilation system (internal abbreviation: RISS3); sample 5: "Dust collector (2008)," from vacuum cleaner (internal abbreviation: RISS2). During the entire time after retrieval, the vacuum cleaner bags and dust filters were stored sealed (never opened since sampling on the ISS), under dry conditions at ambient temperature. Culture controls done from an unused, sterile dust collector and dust filter were negative.

\section{Dust extraction protocol}

For extraction, a $0.9 \% \mathrm{w} / \mathrm{v} \mathrm{NaCl}$ solution was prepared using heat-treated $\mathrm{NaCl}\left(24 \mathrm{~h}, 250{ }^{\circ} \mathrm{C}\right.$, in order to degrade remnants of contaminating DNA) and autoclaved PCR-grade water (LiChrosolv, Merck Millipore). Three $5-10 \mathrm{~cm}^{2}$ pieces of fabric were aseptically cut out of the vacuum cleaner bags and dust filters and submerged in $15 \mathrm{ml}$ 0.9\% DNA-free $\mathrm{NaCl}$ solution.

The fabric pieces in solution were then vortexed for $10 \mathrm{~s}$, manually shaken for $15 \mathrm{~s}$, ultra-sonicated at $40 \mathrm{kHz}$ 
for $2 \mathrm{~min}$, and finally vortexed for $10 \mathrm{~s}$ to detach the dust from the fabric. The fabric was aseptically removed from the solution, and resulting suspension and solid fabric pieces were used for cultivation and molecular analyses.

\section{Cultivation assays}

The solid fabric was placed on aerobic R2A plates ( $\mathrm{pH} 7$; $\mathrm{BDH}$ Prolabo ${ }^{\circ}$ ), whereas the homogeneous dust suspensions were used to inoculate different culture media in duplicates. The media used are given in Table 1. Liquid media were inoculated once with $500 \mu \mathrm{l}$ and once with $250 \mu \mathrm{l}$ of the dust suspension, and solid media were inoculated once with $200 \mu \mathrm{l}$ and once with $100 \mu \mathrm{l}$ of the dust suspension. Since the focus was to isolate bacterial and archaeal isolates, all aerobic media were supplemented with a final concentration of $50 \mu \mathrm{g} / \mathrm{ml}$ nystatin to suppress fungal growth.

Pure cultures were obtained via repeated dilution series in liquid medium and purification streaks on solid media. Positive enrichments of medium $\mathrm{pH} 7$ were transferred to anaerobic R2A plates and then purified by purification streaks.

\section{Identification of isolates}

Partial 16S rRNA genes of the isolates were amplified using the primers 9bF (5'-GRGTTTGATCCTGGCTCAG-3') and 1406uR ( $5^{\prime}$-ACGGGCGGTGTGTRCAA-3'), applying the following cycling conditions: initial denaturation at $95{ }^{\circ} \mathrm{C}$ for $2 \mathrm{~min}$, followed by 10 cycles of denaturing at $96{ }^{\circ} \mathrm{C}$ for $30 \mathrm{~s}$, annealing at $60{ }^{\circ} \mathrm{C}$ for $30 \mathrm{~s}$ and elongation at $72{ }^{\circ} \mathrm{C}$ for $60 \mathrm{~s}$, followed by another $25 \mathrm{cy}$ cles of denaturing at $94{ }^{\circ} \mathrm{C}$ for $30 \mathrm{~s}$, annealing at $60{ }^{\circ} \mathrm{C}$ for $30 \mathrm{~s}$ and elongation at $72{ }^{\circ} \mathrm{C}$ for $60 \mathrm{~s}$, and a final elongation step at $72{ }^{\circ} \mathrm{C}$ for $10 \mathrm{~min}$ [18]. The template was either a small fraction of a picked colony in a colony-PCR assay or 5-20 ng of DNA purified from culture via the peqGOLD Bacterial DNA Kit (peqlab, Germany). The 16S rRNA gene amplicons were Sangersequenced (Eurofins, Germany), and the obtained sequences were classified using the EzTaxon identification service at http://www.ezbiocloud.net/ [19].

The ITS sequence of one fungal isolate was sequenced using the primers ITS1F( $5^{\prime}$-CTTGGTCATTTAGAGG AAGTAA- $\left.3^{\prime}\right)$ and ITS4(5'-TCCTCCGCTTATTGATA TGC-3') and following cycling conditions: initial denaturation at $95{ }^{\circ} \mathrm{C}$ for $10 \mathrm{~min}$, followed by 35 cycles of denaturing at $94{ }^{\circ} \mathrm{C}$ for $60 \mathrm{~s}$, annealing at $51{ }^{\circ} \mathrm{C}$ for $60 \mathrm{~s}$, elongation at $72{ }^{\circ} \mathrm{C}$ for $60 \mathrm{~s}$, and a final elongation step at $72{ }^{\circ} \mathrm{C}$ for $8 \mathrm{~min}$. The amplicons were Sanger-sequenced (Eurofins, Germany), and the obtained sequence was classified using the EzFungi identification.

\section{DNA extraction of original samples and incubation experiment}

After aliquots were removed for cultivation assays, the remaining dust suspension was centrifuged at $16,000 \mathrm{~g}$ to concentrate the remaining dust particles and microorganisms, which were then re-suspended in three aliquots of $0.5 \mathrm{ml}$ of the supernatant. One aliquot was directly frozen at $-80{ }^{\circ} \mathrm{C}$, and one was treated with an end concentration of $50 \mu \mathrm{M}$ propidium monoazide (PMA), to

Table 1 List of used media and conditions

\begin{tabular}{|c|c|c|c|c|c|c|c|}
\hline Medium & Phase & $\mathrm{pH}$ & $\begin{array}{l}\text { Incubation } \\
\text { temperature }\end{array}$ & Gasphase & Abbreviation & $\begin{array}{l}\text { Target } \\
\text { organisms }\end{array}$ & Medium reference \\
\hline R2A agar $\mathrm{pH} 5$ & Solid & 5 & $30^{\circ} \mathrm{C}$ & Aerobic (ambient) & $\mathrm{pH} 5$ & Acidophiles & - \\
\hline $\mathrm{R} 2 \mathrm{~A}$ agar $\mathrm{pH} 9$ & Solid & 9 & $30^{\circ} \mathrm{C}$ & Aerobic (ambient) & $\mathrm{pH} 9$ & Alkaliphiles & - \\
\hline R2A agar $\mathrm{pH} 7$ & Solid & 7 & $30^{\circ} \mathrm{C}$ & Aerobic (ambient) & $\mathrm{pH} 7 \mathrm{~F}$ & Heterotrophs & - \\
\hline RAVAN pH 7 for oligotrophs & Solid & 7 & $30^{\circ} \mathrm{C}$ & Aerobic (ambient) & RAV & Oligotrophs & [72] (modified $\left.{ }^{\mathrm{a}}\right)$ \\
\hline DSMZ_Medium97 for halophiles & Liquid & 7.5 & $40^{\circ} \mathrm{C}$ & Aerobic (ambient) & Halo & Halophiles & DSM 97 (www.dsmz.de) \\
\hline R2A pH 7 liquid & Liquid & 7 & $30^{\circ} \mathrm{C}$ & $\mathrm{N}_{2}$ & $\mathrm{pH} 7 \mathrm{an}$ & Anaerobes & - \\
\hline Medium for methanogens & Liquid & 7 & $40^{\circ} \mathrm{C}$ & $\mathrm{H}_{2} \mathrm{CO}_{2}(80: 20)$ & MS & Methanogens & {$[73]$} \\
\hline $\begin{array}{l}\text { MS supplemented with } 0.1 \% \\
\text { yeast extract and } 0.1 \% \text { acetate }\end{array}$ & Liquid & 7 & $40^{\circ} \mathrm{C}$ & $\mathrm{H}_{2} \mathrm{CO}_{2}(80: 20)$ & MS_sup & Methanogens & - \\
\hline Archaea-supporting liquid medium & Liquid & 7 & $30^{\circ} \mathrm{C}$ & $\mathrm{N}_{2}$ & ASM & Archaea & {$[74]^{b}$} \\
\hline $\begin{array}{l}\text { ASM supplemented with } 0.1 \% \\
\text { yeast extract and } 0.1 \% \text { acetate }\end{array}$ & Liquid & 7 & $30{ }^{\circ} \mathrm{C}$ & $\mathrm{N}_{2}$ & ASM_sup & Archaea & - \\
\hline $\begin{array}{l}\text { Autotrophic all-rounder liquid } \\
\text { medium }\end{array}$ & Liquid & 7 & $30^{\circ} \mathrm{C}$ & $\mathrm{N}_{2} \mathrm{CO}_{2}(80: 20)$ & AAM & Autotrophs & {$[74]^{b}$} \\
\hline $\begin{array}{l}\text { Autotrophic homoacetogen } \\
\text { liquid medium }\end{array}$ & Liquid & 7.5 & $30^{\circ} \mathrm{C}$ & $\mathrm{H}_{2} \mathrm{CO}_{2}(80: 20)$ & $\mathrm{AHM}$ & Autotrophs & {$[74]^{b}$} \\
\hline
\end{tabular}

${ }^{a} 1: 100$ diluted, final concentration of $50 \mathrm{mg} / \mathrm{l}$ sodium pyruvate instead of $20 \mathrm{mg} / \mathrm{l}$ pyruvic acid

bithout addition of antibiotics 
block free DNA of dead cells from downstream applications [20] before freezing.

One aliquot was mixed with $0.5 \mathrm{ml}$ of pre-warmed $30{ }^{\circ} \mathrm{C} \mathrm{LB}$ medium and incubated at $30^{\circ} \mathrm{C}$ for $1.5 \mathrm{~h}$ prior to direct DNA extraction with the aim of increasing the biomass and possibly triggering the germination of spores, which have been reported to resist state-of-the-art DNA extraction methods [5]. DNA was extracted using the modified XS-Buffer method as described previously [15]. DNA concentrations were determined using Qubit, and DNA was afterwards subjected to PCR.

\section{Molecular microbial diversity analysis using next-generation sequencing methods}

To investigate the detectable molecular diversity, we used a "universal" and an Archaea-targeting approach. The 16S rRNA gene amplicons for the universal approach were amplified using Illumina-tagged primers F515 (5' -TCGTCGGCAGCGTCAGATGTGTATAAGA GACAG GTGCCAGCMGCCGCGGTAA-3') and R806 (5'-GTCTCGTGGGCTCGGAGATGTGTATAAGAGA CAG GGACTACHVGGGTWTCTAAT-3') [21]. Archaeal amplicons were obtained via a nested approach [16]: First, a $~ 550$ bp-long $16 \mathrm{~S}$ rRNA gene amplicon was created via the primers Arch344F (5'-ACGGGGYGCAGCAGGCG CGA-3') and Arch915R (5'-GTGCTCCCCCGCCAAT TCCT-3') [22, 23], and in a second PCR, the amplicons for Illumina sequencing were generated by the tagged primers S-D-Arch-0349-a-S-17 (5'-TCGTCGGCAGC GTCAGATGTGTATAAGAGACAG GYGCASCAGKC GMGAAW-3') and S-D-Arch-0519-a-A-16 (5'-GTC TCGTGGGCTCGGAGATGTGTATAAGAGACAG TT ACCGCGGCKGCTG-3) [24], using the purified product of the first PCR as template [16].

The cycling conditions for the universal approach were initial denaturation at $94{ }^{\circ} \mathrm{C}$ for $3 \mathrm{~min}$, followed by 35 cycles of denaturing at $94{ }^{\circ} \mathrm{C}$ for $45 \mathrm{~s}$, annealing at $60{ }^{\circ} \mathrm{C}$ for $60 \mathrm{~s}$ and elongation at $72{ }^{\circ} \mathrm{C}$ for $90 \mathrm{~s}$, and a final elongation step at $72{ }^{\circ} \mathrm{C}$ for $10 \mathrm{~min}$. For the first PCR of the nested archaeal approach, the cycling conditions were initial denaturation at $95{ }^{\circ} \mathrm{C}$ for $2 \mathrm{~min}$, followed by 10 cycles of denaturing at $96{ }^{\circ} \mathrm{C}$ for $30 \mathrm{~s}$, annealing at $60{ }^{\circ} \mathrm{C}$ for $30 \mathrm{~s}$ and elongation at $72{ }^{\circ} \mathrm{C}$ for $60 \mathrm{~s}$, followed by another 15 cycles of denaturing at $94{ }^{\circ} \mathrm{C}$ for $30 \mathrm{~s}$, annealing at $60{ }^{\circ} \mathrm{C}$ for $30 \mathrm{~s}$ and elongation at $72{ }^{\circ} \mathrm{C}$ for $60 \mathrm{~s}$, and a final elongation step at $72{ }^{\circ} \mathrm{C}$ for $10 \mathrm{~min}$. For the second amplification the cycling conditions were initial denaturation at $95^{\circ} \mathrm{C}$ for $5 \mathrm{~min}$, followed by 25 cycles of denaturing at $95{ }^{\circ} \mathrm{C}$ for $40 \mathrm{~s}$, annealing at $63{ }^{\circ} \mathrm{C}$ for $120 \mathrm{~s}$ and elongation at $72{ }^{\circ} \mathrm{C}$ for $60 \mathrm{~s}$, and a final elongation step at $72{ }^{\circ} \mathrm{C}$ for $10 \mathrm{~min}$.

Library preparation and sequencing were carried out at the Core Facility Molecular Biology at the Center for Medical Research at the Medical University Graz, Austria. In brief, DNA concentrations were normalized using a SequalPrep ${ }^{\text {Tw }}$ normalization plate (Invitrogen), and each sample was indexed with a unique barcode sequence (8 cycles index PCR). After pooling of the indexed samples, a gel cut was carried out to purify the products of the index PCR. Sequencing was done using the Illumina MiSeq device and MS-102-3003 MiSeq ${ }^{\circ}$ Reagent Kit v3-600cycles $(2 \times 251$ cycles $)$.

\section{Antimicrobial susceptibility tests}

Nineteen of the isolates were selected for antimicrobial susceptibility testing and heat-shocks based on their phylogeny and on differences in phenotypical appearance. Antimicrobial susceptibility testing for selected, clinically relevant antibiotics (Table 2) was performed using Etest ${ }^{\circ}$ reagent strips (Biomérieux, Germany) according to instructions of the manufacturer. Since there were no species specific breakpoints available, MICs were interpreted according to EUCAST guideline table "PK/PD (Non-species related) breakpoints" [25].

In brief, overnight cultures (2-3-day cultures for slower-growing bacteria) were suspended in $0.9 \%$ saline to a turbidity of McFarland 0.5 . One hundred microliters of this suspension was plated on standardized Müller-Hinton agar for antimicrobial susceptibility testing (Becton Dickinson). Etest ${ }^{\circ}$ reagent strips were placed on the plates followed by aerobic incubation for $18+/-2 \mathrm{~h}$ at $34{ }^{\circ} \mathrm{C}$. Two strains were tested four times (in duplicate) on $\mathrm{R} 2 \mathrm{~A} \mathrm{pH} 7$ and incubated for $48 \mathrm{~h}$ at $34{ }^{\circ} \mathrm{C}$, because of their inability to grow on Müller Hinton medium and their intrinsic slow growth.

\section{Heat-shock resistance test}

The heat-shock test was carried out according to ESA standards [26]. This test is usually applied to quantify the bioburden of spacecraft, in order to identify hardy microorganisms that are potentially able to survive a spaceflight to other solar bodies. In brief, single colonies of 1-2-day old cultures were suspended in two test tubes containing $2.5 \mathrm{ml}$ sterile phosphate buffered saline (PBS). As a control, one tube was kept at room temperature during the procedure. The other tube was placed in an $80^{\circ} \mathrm{C}$ water bath and exposed for $15 \mathrm{~min}$. Samples were immediately cooled down on ice for 5 min after incubation time.

The temperature was monitored using a separate pilot tube containing $2.5 \mathrm{ml}$ PBS also in the water bath. Afterwards, $0.5 \mathrm{ml}$ of the heat-shocked suspension and $0.5 \mathrm{ml}$ of the room temperature suspension were plated and incubated at $30{ }^{\circ} \mathrm{C}$ for 3 days $(72 \mathrm{~h})$.

\section{Negative controls}

Negative controls were performed thoroughly. Cultivation, extraction, PCR, and sequencing controls were analyzed in parallel with the processing of the samples. 
Table 2 Antibiotics used in this experiment (additional information from [75] and [76]

\begin{tabular}{|c|c|c|c|c|}
\hline Antibiotic substance & Type & Mechanism of action & Target group & $\begin{array}{l}\text { Concentrations } \\
\text { applied }(\mu \mathrm{g} / \mathrm{ml})\end{array}$ \\
\hline Amoxicillin/clavulanic acid & $\begin{array}{l}\beta \text {-Lactam antibiotic (penicillin) } \\
\text { and } \beta \text {-lactamase inhibitor }\end{array}$ & $\begin{array}{l}\text { Inhibits cell wall synthesis; } \\
\text { bactericidal against growing } \\
\text { bacteria }\end{array}$ & Gram+ and Gram- bacteria & $0.016-256$ \\
\hline Ampicillin & $\beta$-Lactam antibiotic penicillin & $\begin{array}{l}\text { Inhibits cell wall synthesis; } \\
\text { bactericidal against growing } \\
\text { bacteria }\end{array}$ & Gram+ and Gram- bacteria & $0.016-256$ \\
\hline Cefotaxime & $\begin{array}{l}\beta \text {-Lactam antibiotic; } \\
\text { cephalosporin }\end{array}$ & $\begin{array}{l}\text { Inhibits cell wall synthesis; } \\
\text { bactericidal against growing } \\
\text { bacteria }\end{array}$ & Gram+ and Gram- bacteria & $0.016-256$ \\
\hline Ceftriaxone & $\begin{array}{l}\beta \text {-Lactam antibiotic; } \\
\text { cephalosporin }\end{array}$ & $\begin{array}{l}\text { Inhibits cell wall synthesis; } \\
\text { bactericidal against growing } \\
\text { bacteria }\end{array}$ & Gram+ and Gram- bacteria & $0.016-256$ \\
\hline Ciprofloxacin & Fluoroquinolone & $\begin{array}{l}\text { Inhibits bacterial DNA gyrase; } \\
\text { bactericidal }\end{array}$ & Gram+ and Gram- bacteria & $0.002-32$ \\
\hline Clarithromycin & Macrolide & $\begin{array}{l}\text { Inhibits protein synthesis; } \\
\text { bacteriostatic }\end{array}$ & Gram+ and Gram- bacteria & $0.016-256$ \\
\hline Clindamycin & Lincosamide & $\begin{array}{l}\text { inhibits protein synthesis; } \\
\text { bacteriostatic }\end{array}$ & $\begin{array}{l}\text { Gram+ and anaerobic } \\
\text { Gram- bacteria }\end{array}$ & $0.016-256$ \\
\hline Colistin & $\begin{array}{l}\text { Polypeptide antibiotic; } \\
\text { polymyxin }\end{array}$ & $\begin{array}{l}\text { Attacks cell membrane; } \\
\text { bactericidal }\end{array}$ & Gram-bacteria & $0.016-256$ \\
\hline Doxycycline & $\begin{array}{l}\text { Polyketide antibiotic; } \\
\text { tetracycline }\end{array}$ & $\begin{array}{l}\text { inhibits protein synthesis; } \\
\text { bacteriostatic; }\end{array}$ & Gram+ and Gram- bacteria & $0.016-256$ \\
\hline Gentamicin & Aminoglycoside & $\begin{array}{l}\text { inhibits protein synthesis; } \\
\text { bactericidal }\end{array}$ & Gram- and some Gram+ bacteria & $0.016-256$ \\
\hline Levofloxacin & Fluoroquinolone & $\begin{array}{l}\text { Inhibits bacterial DNA gyrase; } \\
\text { bactericidal }\end{array}$ & Gram+ and Gram- bacteria & $0.002-32$ \\
\hline Linezolid & Oxazolidinone & $\begin{array}{l}\text { inhibits protein synthesis; } \\
\text { bacteriostatic }\end{array}$ & Gram+ bacteria & $0.016-256$ \\
\hline Meropenem & $\begin{array}{l}\beta \text {-Lactam antibiotic } \\
\text { carbapenem }\end{array}$ & $\begin{array}{l}\text { Inhibits cell wall synthesis; } \\
\text { bactericidal against growing } \\
\text { bacteria }\end{array}$ & Gram+ and Gram- bacteria & $0.002-32$ \\
\hline Moxifloxacin & Fluoroquinolone & $\begin{array}{l}\text { Inhibits bacterial DNA gyrase; } \\
\text { bactericidal; }\end{array}$ & Gram+ and Gram- bacteria & $0.002-32$ \\
\hline Penicillin G & $\begin{array}{l}\beta \text {-Lactam antibiotic } \\
\text { penicillin }\end{array}$ & $\begin{array}{l}\text { Inhibits cell wall synthesis; } \\
\text { bactericidal against growing } \\
\text { bacteria }\end{array}$ & Gram+ bacteria & $0.016-256$ \\
\hline Trimethoprim/sulfamethoxazole & $\begin{array}{l}\text { Dihydrofolate reductase } \\
\text { inhibtor and sulfonamide }\end{array}$ & $\begin{array}{l}\text { Inhibits tetrahydrofolate } \\
\text { synthesis; bactericidal }\end{array}$ & Gram+ and Gram- bacteria & $0.002-32$ \\
\hline Vancomycin & Glycopeptide antibiotic & $\begin{array}{l}\text { Inhibits cell wall synthesis; } \\
\text { bactericidal against growing } \\
\text { bacteria }\end{array}$ & Gram+ bacteria & $0.016-256$ \\
\hline
\end{tabular}

Cultivation controls were performed on two levels. First, the same, unused material (dust collector, dust filter material) as was used on the ISS was placed on cultivation medium. Secondly, extraction blanks were processed in parallel to the ISS material. All cultivation controls were negative (no growth of colonies). Extraction blanks used for DNA extraction, PCR, and sequencing revealed a low number of ribosomal sequence variants (RSVs, see below). These RSVs were removed from all datasets, if present in the samples (the removed RSVs are highlighted in Additional file 1: Table S1 and Additional file 2: Table S2).

\section{Bioinformatical analysis and data processing}

Demultiplexed, paired reads were processed in $\mathrm{R}$ (version 3.2.2) using the R package DADA2 as described previously [27]. In brief, sequences were quality checked, filtered, and trimmed to a consistent length of $\sim 270$ bp ("universal" primer set) and 140 bp ("archaea" primer set). The trimming and filtering were performed on paired reads with a maximum of two expected errors per read $(\operatorname{maxEE}=2)$. Passed sequences were dereplicated and subjected to the DADA2 algorithm to identify indel-mutations and substitutions. After merging paired reads and chimera filtering, the sequences were assigned to a taxonomy using the RDP 
classifier and the SILVA v.14 trainset. The visualization was carried out using the $\mathrm{R}$ package phyloseq [28, 29], and metabolic pathways were predicted using the $R$ package Tax4Fun [30]. Biostatistical analyses were performed using STAMP [31].

In contrast to previously described data processing pipelines such as QIIME [32] and mothur [33], the DADA2 output table was not produced based on a clustering step and thus no operational taxonomic units (OTUs) were generated. Each row in the DADA2 output table corresponds to a non-chimeric inferred sample sequence, each with a separate taxonomic classification (ribosomal sequence variants; RSVs) [27]. In addition, the merging step occurs after denoising, which increases accuracy.

In order to compare our results to the recently published microbial community of US American ISS HEPA filter particulates and vacuum cleaner bag components (ISS Debris) [4], the protocol was changed as follows: Checinska et al. could not merge the forward and reverse reads using the software mothur [33] and also the DADA2 approach, which we applied, did not result in a sufficient amount of merged sequences (data not shown). For the sake of comparability, we reanalyzed the datasets of Checinksa et al. 2015 containing dust samples (i.e., "ISS HEPA total," "ISS HEPA viable," "ISS Debris total," and "ISS Debris total") and our dataset in parallel, by using only high quality forward reads (length 130 bp, quality score: >30). This approach was in congruence with the data processing as described in Checinska et al. 2015 [4].

For phylogenetic tree construction, the sequence dataset was aligned and processed in MEGA 6 [34]. Alignment was minimized and cropped to the core area, on which tree calculation (maximum likelihood) was based on. The obtained tree and the data were visualized using iTOL [35]. The Venn diagram was created using the online tool InteractiVenn [36].

\section{Data availability}

Sequencing datasets as well as partial 16S rRNA gene sequences of bacterial isolates and ITS1 sequence of the fungal isolate were submitted to the European Nucleotide
Archive and are publicly available. Sequencing datasets are assigned the study project number PRJEB14961, and samples are named according to internal abbreviations RISS1-5 as described in the chapter "Origin of samples." The accession numbers assigned to the partial 16S rRNA gene sequences and ITS1 sequence are LT617056LT617090.

\section{Results}

The International Space Station is an extreme working and living environment. It is completely sealed off from the outside and thus exhibits a unique combination of chemical and physical parameters that act on all abiotic and biotic matter. To date, the effect on the human body or on the microbial community therein is only sparsely studied. However, we hypothesize that the microbial community thriving and surviving inside of the International Space Station becomes adapted to desiccation and other stresses. For this reason, we analyzed 8-12-year-old dust samples from Russian ISS modules with respect to the cultivable portion of the microorganisms and the microbial community composition of these old samples. The retrieved microbial isolates were analyzed with respect to their resistance towards heatshocks and antibiotics. Overall, our data were compared to recently obtained results from present day ISS samples [4].

\section{Numerous bacteria survive long-term archiving of International Space Station dust samples}

We applied a variety of different culture media to retrieve microbial isolates from ISS samples. The culture media supported slightly acidotolerant, alkalitolerant, and oligotrophic microorganisms, respectively, but also provided growth conditions for autotrophs and anaerobic microbes. Overall, 85 bacterial isolates were obtained (Table 3 ) which could be assigned to eight genera. In spite of the nystatin applied to prevent fungal growth, we also obtained one single fungal isolate from "Dust filter-2 (2004)" on $\mathrm{R} 2 \mathrm{~A} \mathrm{pH}$ 9. The fungal isolate was classified according to its internal transcribed spacer (ITS) sequence as Ulocladium botrytis.

Table 3 Number of bacterial isolates obtained on different cultivation media

\begin{tabular}{|c|c|c|c|c|c|c|c|c|}
\hline \multirow[b]{2}{*}{ Sample origin } & \multicolumn{8}{|c|}{ Number of microbial isolates obtained on culture media } \\
\hline & $\mathrm{R} 2 \mathrm{~A} \mathrm{pH} 5$ & $\mathrm{R} 2 \mathrm{~A} \mathrm{pH} 9$ & $\mathrm{R} 2 \mathrm{~A} \mathrm{pH} 7 \mathrm{~F}$ & R2A pH 7 anox & DSM97 "Halo" & MS_sup & ASM_sup & Total \\
\hline 1: Dust filter-1 (2004) & 5 & 0 & 3 & 0 & 0 & 0 & 0 & 8 \\
\hline 2: Dust filter-2 (2004) & 5 & 0 & 2 & 0 & 0 & 0 & 0 & 7 \\
\hline 3: Dust collector (2004) & 10 & 7 & 3 & 3 & 0 & 2 & 1 & 26 \\
\hline 4: Dust filter (2008) & 5 & 1 & 4 & 0 & 0 & 0 & 0 & 10 \\
\hline 5: Dust collector (2008) & 14 & 11 & 3 & 3 & 1 & 2 & 0 & 34 \\
\hline Total & 39 & 19 & 15 & 6 & 1 & 4 & 1 & 85 \\
\hline
\end{tabular}


The highest percentage of isolates (46\%) was obtained from $\mathrm{R} 2 \mathrm{~A}$ agar with $\mathrm{pH} 5$, thus indicating a preference of slightly acidic growth conditions compared to $\mathrm{pH} 9$ (22\%) and $\mathrm{pH} 7$ (18\%). Additional growth was observed at $\mathrm{pH} 7$ under anoxic conditions, whereas only a few isolates were obtained under high-salt concentrations $(18 \% \mathrm{NaCl}$, Salinibacillus aidingensis), or in liquid MS_sup or ASM_sup medium. Only seven isolates were obtained from the "Dust filter-2 (2004)" sample, and the highest amount of isolates was obtained from the "Dust collector (2008)" sample.

Overall, 34 bacterial isolates were found to be unique with respect to their $16 \mathrm{~S}$ rRNA gene, which are displayed according to their phylogeny, preferred culture medium and sample origin in Fig. 1.

Notably, isolates from dust filter samples were nonspore-forming Proteobacteria (Cupriavidus, Methylobacterium, Bradyrhizobium) and Actinobacteria (Micrococcus), whereas spore-forming species (Firmicutes, mainly Bacillus representatives) were isolated from dust collector samples only. These 34 different bacterial strains were assigned to 17 different species, which are listed in Additional file 3: Table S3, together with isolates obtained by Checinska et al. 2015 [4].

ISS isolates were found to be resistant against desiccation, heat-shock, and some common clinically applied antibiotics All isolates obtained had been stored in dust/dust filters for at least 8 years before the cultivation experiments were performed. Since they were stored under dry conditions, all cultivated strains can be assumed to be desiccation resistant.

For the heat-shock resistance and antibiotic susceptibility tests, 19 representative isolates were selected from our pool. Following the NASA and ESA guidelines for bioburden detection in clean rooms and on spacecraft [26], cultures were exposed to a heat-shock (15 min, $80{ }^{\circ} \mathrm{C}$ ). This heat-shock is currently used by the named space agencies in order to determine the resistance to environmental stresses and to analyze whether

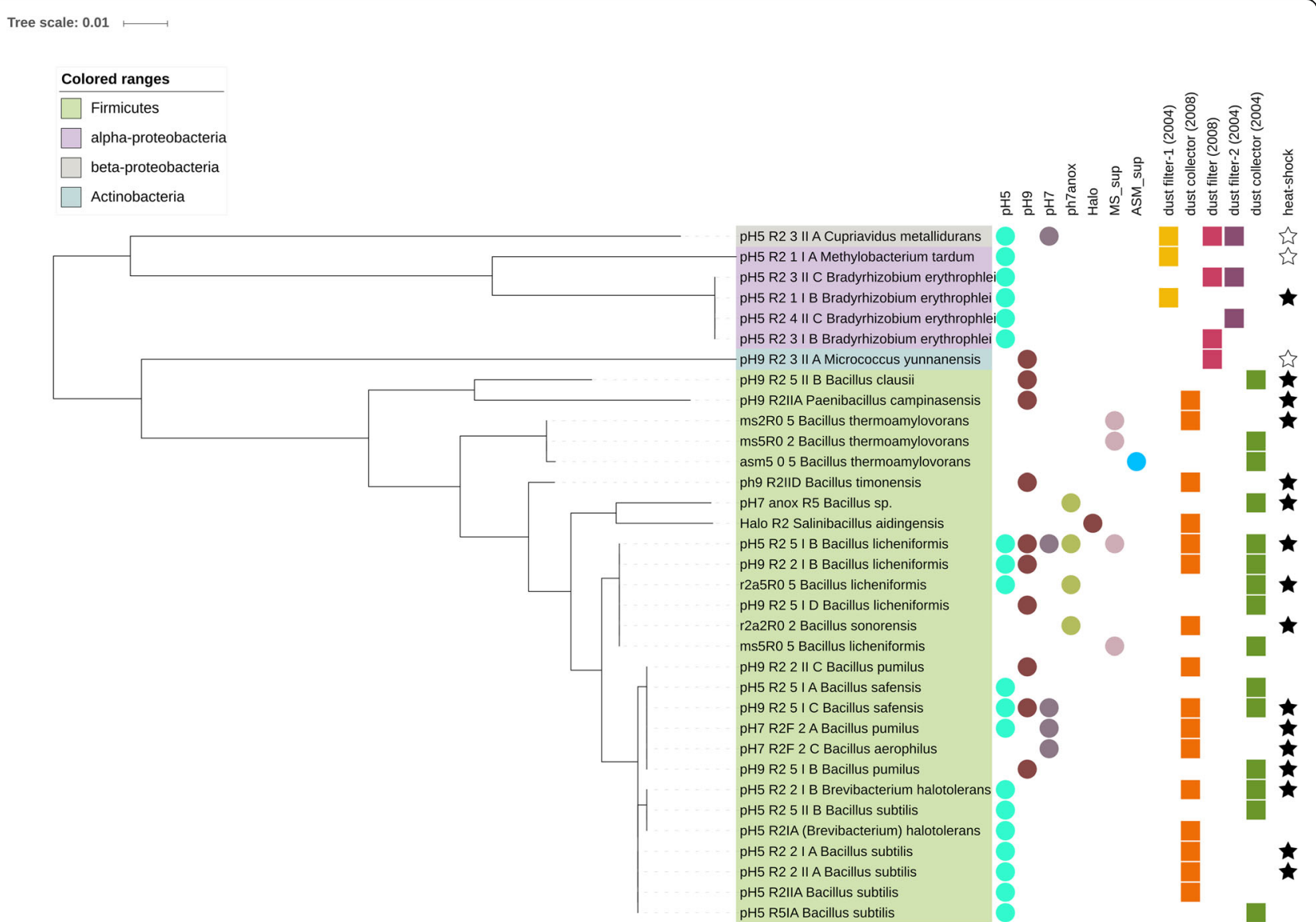

Fig. 1 Maximum-likelihood tree based on the unique 16S rRNA gene sequences of the ISS isolates. Circles indicate the medium they were cultivated in. Squares refer to the sample origin. Stars indicate the heat-shock resistance of the isolates (filled star. survived heat-shock at $80^{\circ} \mathrm{C}$ for 15 min; empty star: did not survive heat-shock; others were not tested). Tree was constructed using MEGA6 [34] and displayed by iToL [35] 
microorganisms are possible candidates to survive space flight for planetary protection considerations. Sixteen out of 19 isolates survived the heat-shock treatment, as indicated in Fig. 1 (filled stars). All sporeforming microorganisms of the genus Bacillus and one Paenibacillus were able to survive the treatment, whereas Methylobacterium, Cupriavidus, and Micrococcus could not be re-grown afterwards. Notably, a few cells (three colonies instead of bacterial lawn as observed for spore-formers and positive control) of Bradyrhizobium, although representing a non-spore-forming Alphaproteobacterium, survived the heat-shock.

Seventeen clinically relevant antibiotics (see Table 2) were selected for susceptibility testing of the 19 selected microbial isolates. When applicable, the antimicrobial resistance was assessed using the most recent update of the EUCAST expert rules ([37]; www.eucast.org; Breakpoint Table for bacteria v6.0, January 2016). The results of the antibiotics-resistance tests are summarized in Table 4 (see also Additional file 4: Figure S1).

All strains were transferred to Müller-Hinton agar, and antibiotic tests were performed using this medium, with the exception of two strains: Methylobacterium tardum and Bradyrhizobium erythrophlei, as they resisted growing under these conditions. For these two strains, we used R2A and an incubation time of $48 \mathrm{~h}$. Both strains revealed, under adapted conditions, robust resistances against numerous antibiotics. All strains revealed resistance against at least one antibiotic compound above the non-species specific EUCAST threshold, except Micrococcus yunnanensis.

We tested six different $\beta$-lactam antibiotics of which the cephalosporins cefotaxime and ceftriaxone as well as penicillin $G$ were found to be most ineffective against the ISS isolates, since almost all microbial strains exceeded their resistance breakpoints or at least the intermediate breakpoints (see Table 4 and Additional file 4: Figure S1A).

\section{Molecular, NGS-based analysis revealed the presence of a broad bacterial and archaeal diversity}

Aliquots of the same samples that were used for the cultivation approach were subjected to molecular analyses. We followed three different approaches. (A) Samples were processed untreated, (B) Samples were exposed to liquid growth medium (LB) for $1.5 \mathrm{~h}\left(30^{\circ} \mathrm{C}\right)$ in order to increase biomaterial and trigger spore germination (incubated samples), (C) Samples were treated with propidium monoazide (PMA) to mask background DNA from disrupted cells [38]. PMA-treated samples (C) did not reveal any signals after DNA extraction and PCR, using "universal" and archaea-targeting primer sets, although cultivation from these samples was successful. However, all samples that underwent the incubation treatment (B) resulted in reasonable PCR product yields. Untreated samples (A) resulted in positive archaeal amplicon generation for four out of five samples, namely "dust filter-1 (2004)," "dust collector (2004)," "dust filter (2008)," and "dust collector (2008)"; three out of five samples resulted in positive universal amplicon generation ("dust filter-1 (2004)," "dust filter (2008)," "dust collector (2008)").

Universal and archaeal amplicons were subjected to next-generation sequencing (Illumina MiSeq). Raw reads were processed using DADA2. It should be noted that DADA2 does not perform a clustering step, thus does not produce operational taxonomic units (OTUs). Each sequence obtained corresponds to a unique taxonomic classification (ribosomal sequence variant; RSV).

In total, 203,667 high quality sequence counts were obtained of the four positive archaeal approaches (length $>140 \mathrm{bp}$ ), representing nine different RSVs. Among the four samples, the "dust collector (2004)" yielded the highest number of sequence counts $(102,782)$. The "dust filter-1 (2004)" sample and the "dust collector (2008)" sample resulted in 71,203 and 29,600 archaeal sequence counts, respectively, whereas the lowest number was observed in the "dust filter (2008)" sample (82 sequence counts). As a consequence, the "dust filter (2008)" sample revealed the lowest richness, the lowest Shannon Index, and the lowest InvSimpson Index (Additional file 4: Figure S2). The highest archaeal richness was observed in the "dust filter-1 (2004)" sample (8 RSVs).

Overall, sequences assigned to Thaumarchaeota (Nitrososphaera sp.), Euryarchaeota (Methanobrevibacter sp.), and Woesearchaeota were found in the ISS samples (Fig. 2). Methanobrevibacter sequences could be detected in a very low abundance in "dust filter-1 (2004)" and also in "dust filter (2008)," where all obtained 82 sequence reads belonged to the genus Methanobrevibacter (see also Additional file 5: Table S4). Unclassified Woesearchaeota signatures were found in "dust filter1 (2004)" at very low abundance $(<0.1 \%$ of sample) and in "dust collector (2008)" with a very high abundance ( $>99.9 \%$ of sample; $14.5 \%$ of all archaeal sequence counts). Nitrososphaera signatures (Thaumarchaeota) were detected in two samples in a high abundance ("dust filter-1 (2004)" and "dust collector (2004)"), but were not observed in other samples. Furthermore, thaumarchaeal signatures were also detected in sequence data derived from amplicons produced with the universal primer pair. In particular, they were detected in untreated samples of "dust filter-1 (2004)," in agreement with the archaea-targeting approach mentioned above. $48.5 \%$ of the universal 16S rRNA gene sequences derived from this sample were assigned to Thaumarchaeota, soil crenarchaeotic group (SCG), with Nitrososphaera as the main genus. However, all other samples containing archaeal reads revealed only very low abundances $(<1 \%)$. Those 


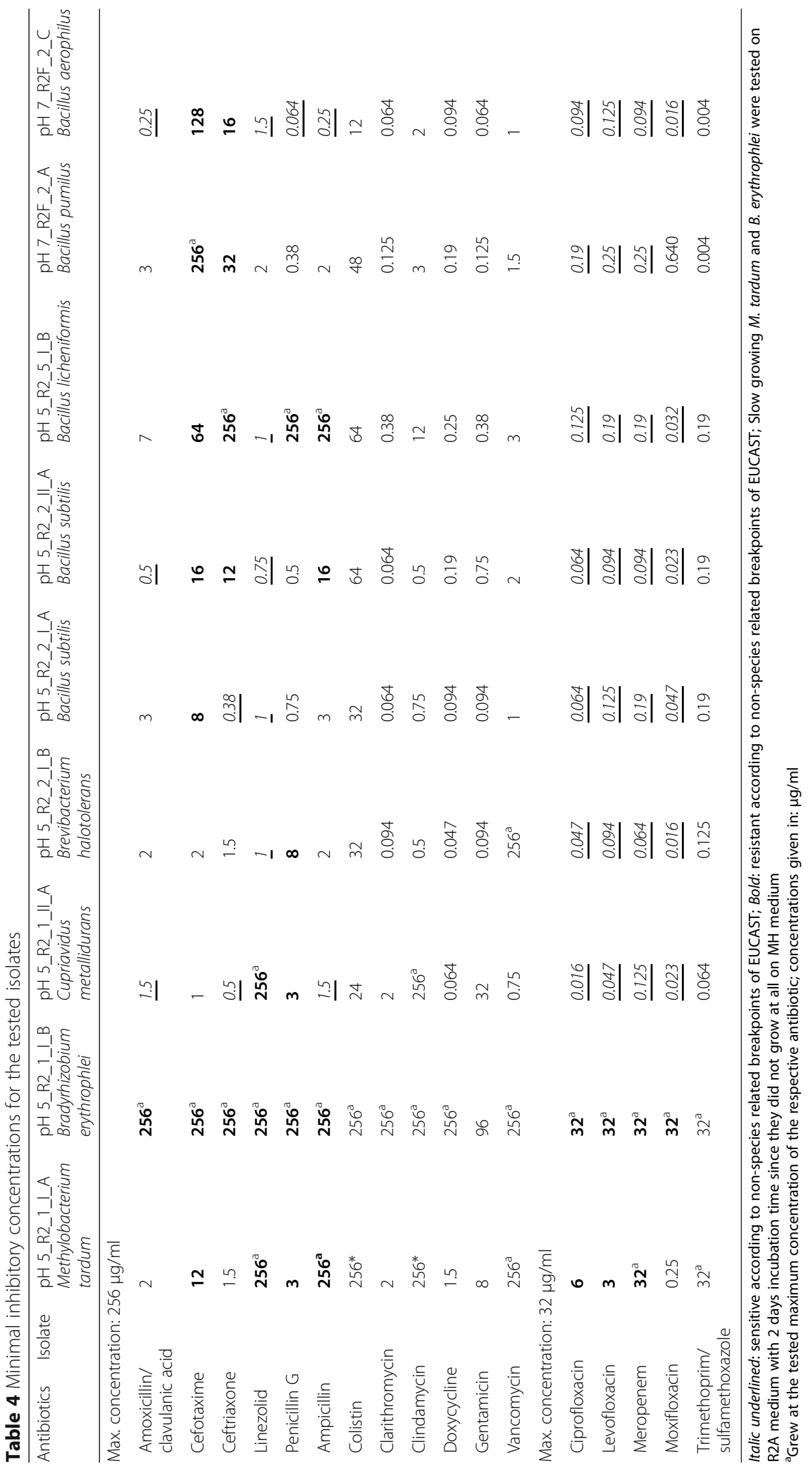




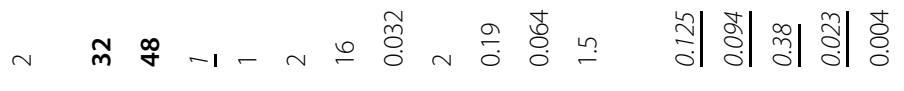

$$
\begin{aligned}
& \text { 至 }
\end{aligned}
$$

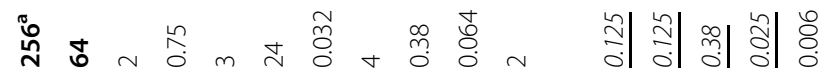

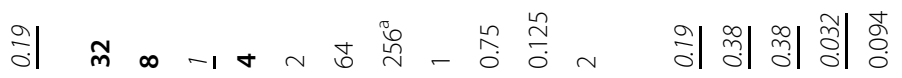

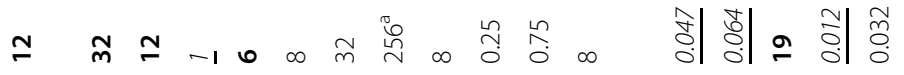

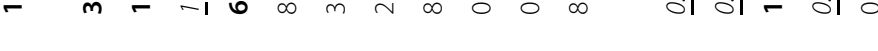

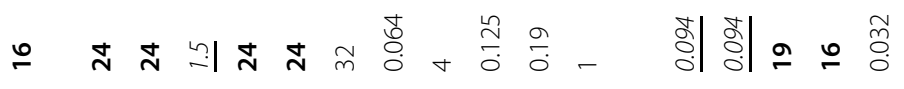

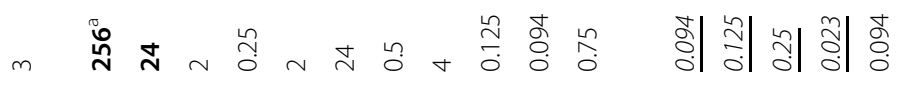

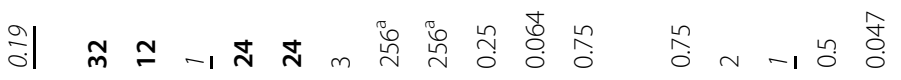

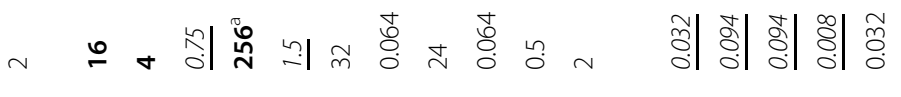

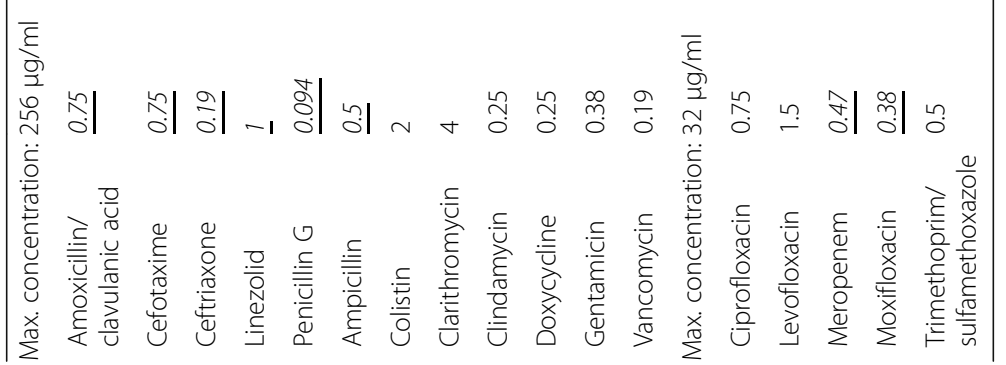




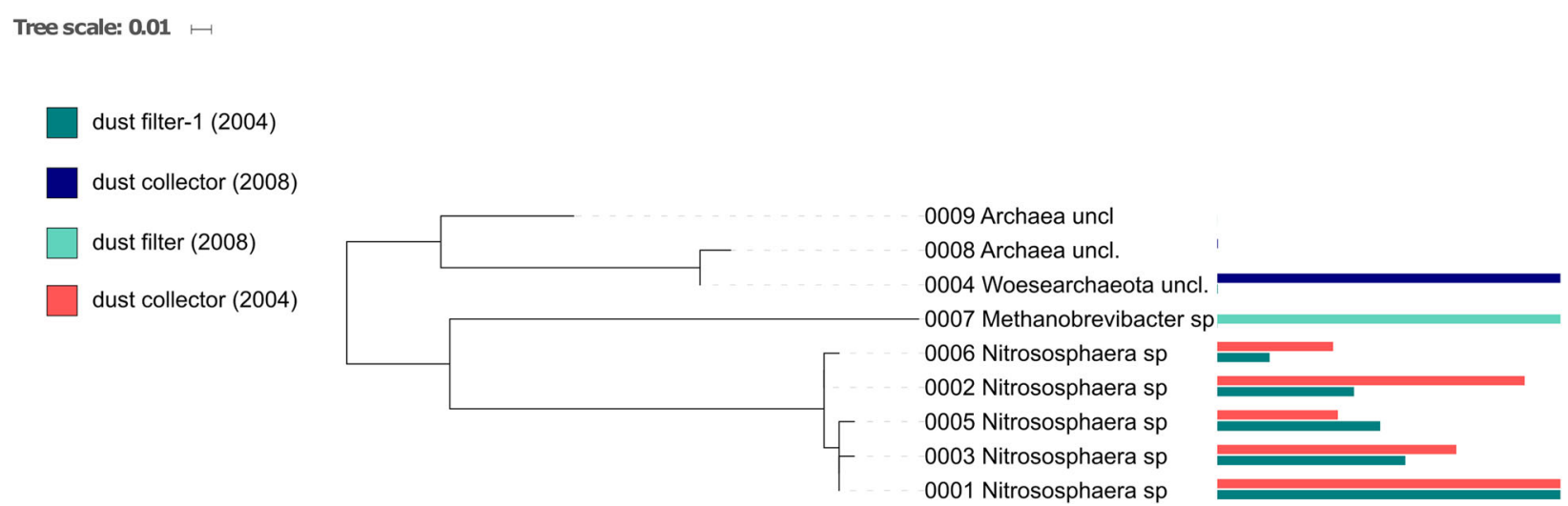

Fig. 2 Archaeal maximum-likelihood tree: detected taxa and their abundance in different samples of ISS

were mainly assigned to Euryarchaeota (Methanobacteria), represented by Methanobrevibacter $(0.6 \%$ of incubated "dust filter-2 (2004)"), Methanosphaera, Methanobacterium, or not further classified members of the Woesearchaea $(0.5 \%$ of "dust collector (2008)"; in congruence with the high amount of woesearchaeal reads obtained by the archaeal primer set for this sample). "Dust collector (2004)," the other sample with a high abundance of Nitrososphaera when sequenced with archaeal primers, did not deliver any sequences with the universal primer pair. In the incubated "dust filter-1 (2004)" and "dust collector (2004)," we could also not detect Thaumarchaeota with the universal primer set. In total, NGS based on the "suniversal" primer set generated 227,439 high-quality sequences (Additional file 6: Table S5). Sequences obtained by the universal primer approach were classified using the SILVA database [39], and community composition was summarized (see Fig. 3). In the following, we distinguish between untreated and incubated samples, referring to treatments $\mathrm{A}$ and $\mathrm{B}$, respectively, as indicated above. In untreated samples, most signatures were assigned to phyla Thaumarchaeota (48.7\%; "dust filter-1 (2004)"), Actinobacteria (36\% in "dust collector (2008)") and Firmicutes (44.2\% in "dust filter (2008)" sample)). In incubated samples, the dominant phyla were Actinobacteria, Firmicutes, and Proteobacteria. Signatures of Bacteroidetes (lowest abundance in incubated "dust filter-1 2004" sample; highest abundance in untreated "dust filter 2008" sample) were also found in all samples. Further details are shown in Fig. 3.

At class level, the most abundant taxa were assigned to thaumarchaeal soil crenarchaeotic group (SCG), Actinobacteria, Bacilli, Gammaproteobacteria, and Betaproteobacteria. In incubated and untreated "dust filter (2008)" samples, there was no remarkable difference with respect to the microbial community composition. Five genera were identified whose abundance appeared significantly different in incubated and untreated samples (paired White test, $p>0.001$, confidence $>0.95$, see Additional file 4: Figure S3): Facklamia (Lactobacillales; higher abundance in untreated sample), Coprococcus_1 (Clostridiales; higher abundance in untreated sample), Leuconostoc (Bacilli; higher abundance in untreated sample); Coproccocus_3 (higher abundance in incubated sample), and an unclassified member of the family Ruminococcaceae (higher abundance in incubated sample).

In total, we could identify signatures of 23 microbial genera shared by untreated and corresponding incubated samples (Fig. 4). These taxa were mostly assigned to Actinobacteria (4), Clostridia (6), Bacilli (5), and Alpha/-Gammaproteobacteria (2 and 3, respectively). To compare community composition among samples, a beta-diversity matrix (i.e., Bray-Curtis distance (unweighted)) was computed and evaluated using principal coordinate analysis (PCoA, see Fig. 4). Untreated "dust filter (2008)" was found to reveal a similar microbial community composition as the incubated "dust filter (2008)" sample and the incubated "dust collector (2008)" sample. In contrast, the microbial community of the untreated "dust filter-1 (2004)" sample and the "dust collector (2008)" sample appeared to be distinct.

\section{Comparison between cultivation-based microbial diversity} and molecular analysis emphasizes the need of cultivation For the comparison of cultivation-based microbial diversity with the overall microbial diversity, we focused on the 34 unique isolates. The partial $16 \mathrm{~S}$ rRNA gene sequences of individual, unique isolates were compared pairwise with all Illumina sequences belonging to the same genus. The sequences were considered to belong to the same species if they exceeded the similarity threshold of $99 \%$. Almost all isolates could be retrieved in the sequencing results (see Fig. 5), but the isolates belonging to the genus Bradyrhizobium and Salinibacillus could not be detected in the sequence 


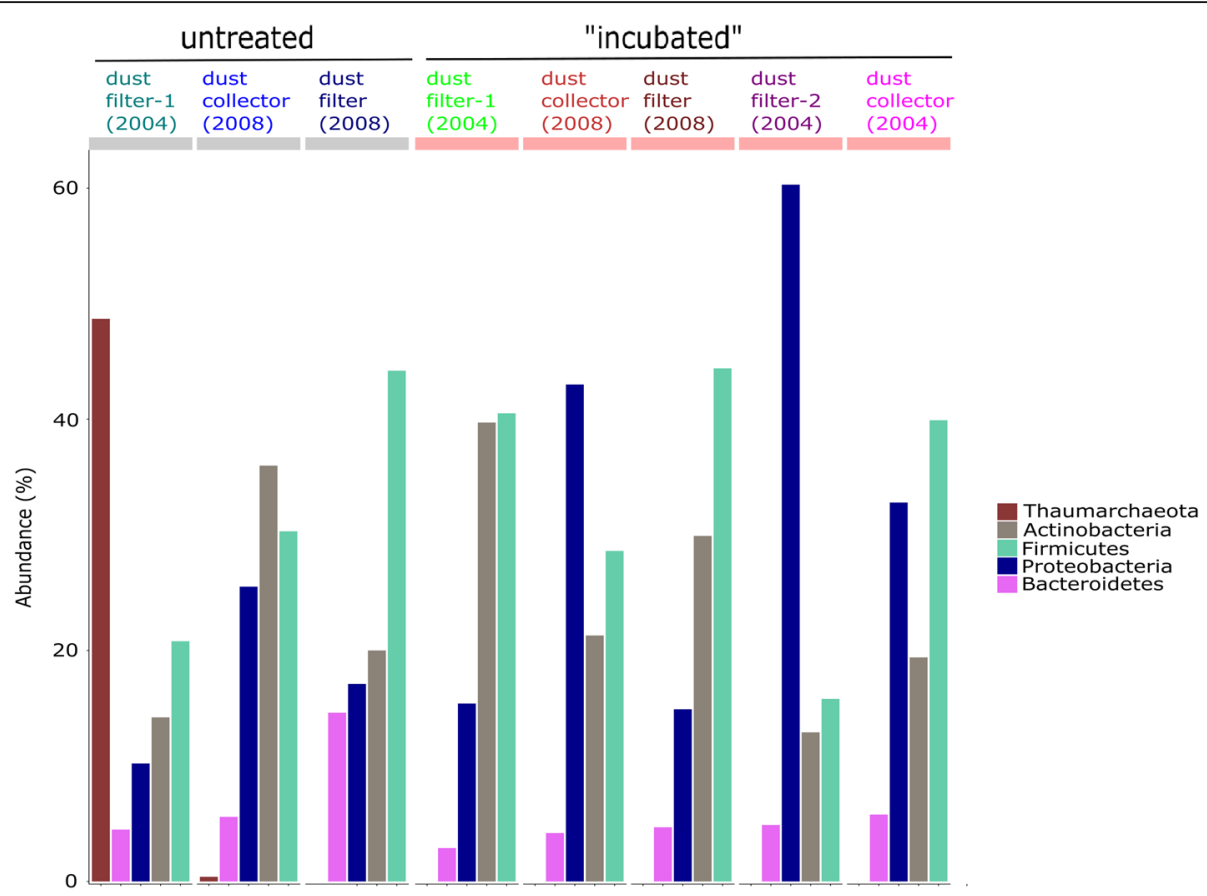

Fig. 3 Taxonomic profiles of the microbial communities from Russian ISS samples at phylum level. The five most abundant phyla are depicted. We discriminate between untreated and incubated samples. Total counts are given in \% ("Abundance")
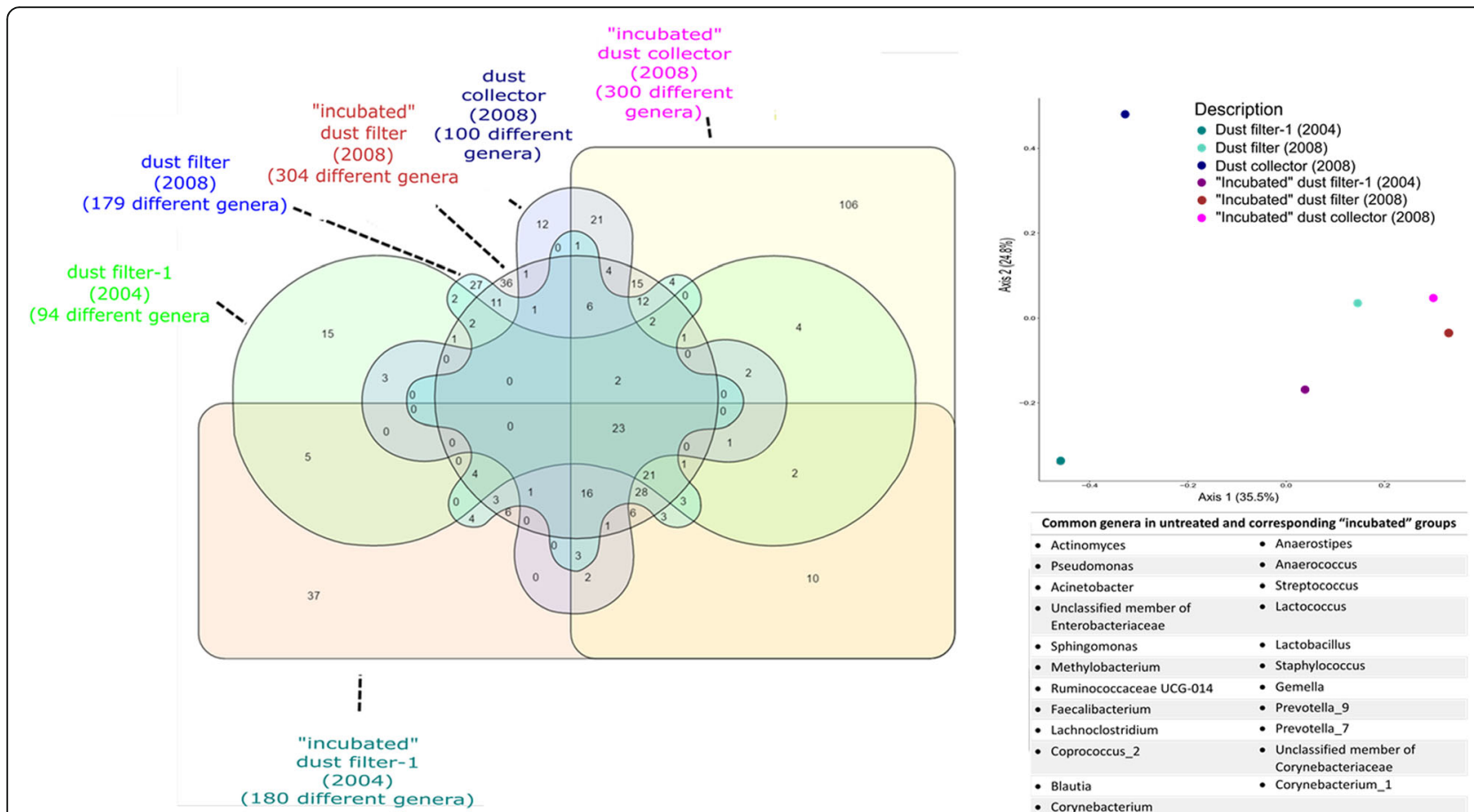

Common genera in untreated and corresponding "incubated" groups

- Actinomyces

- Anaerostipes

- Pseudomonas - Anaerococcus

- Acinetobacter - Streptococcus

- Unclassified member of

- Lactococcus

- Lactobacillus

- Methylobacteri

- Staphylococcus

- Ruminococcaceae UCG-014 Gemella

- Faecalibacterium $\quad$ Prevotella_9

- Unclassified member of

- Coprococcus_2 $\quad$ Unclassified member

- Blautia - Corynebacterium_

Fig. 4 Venn diagram depicting common genera in untreated groups and their corresponding incubated counterparts. In total, signatures of 23 genera were common in all six samples. The PCoA plot on the right side is depicting the dissimilarity between incubated and untreated samples using the unweighted Bray-Curtis distance. No clear cluster pattern is visible between the two groups 
pool. In general, most isolates could be obtained from the "dust collector (2004)" and the "dust collector (2008)," whereas the highest counts of sequences could be obtained in the "dust filter-1 (2004)" (Cupriviadus metallidurans, $31.2 \%$ of all sequence reads). Remarkably, a high proportion of different Bacillus species could be isolated, in accordance with the total sequence count retrieved for all samples. However, half of the isolates were cultivated out of the "dust collector (2004)," where no sequences for Bacillus were detected at all. The non-conformity between sequencing data and isolated cultures is also true for species of Paenibacillus and Micrococcus. Brevibaterium signatures could be obtained in four of six sampling sites, and Brevibacterium isolates could be cultivated out of one sampling site. Methylobacterium, in contrast, was detected throughout all sampling sites but could be isolated out of only one sampling site.

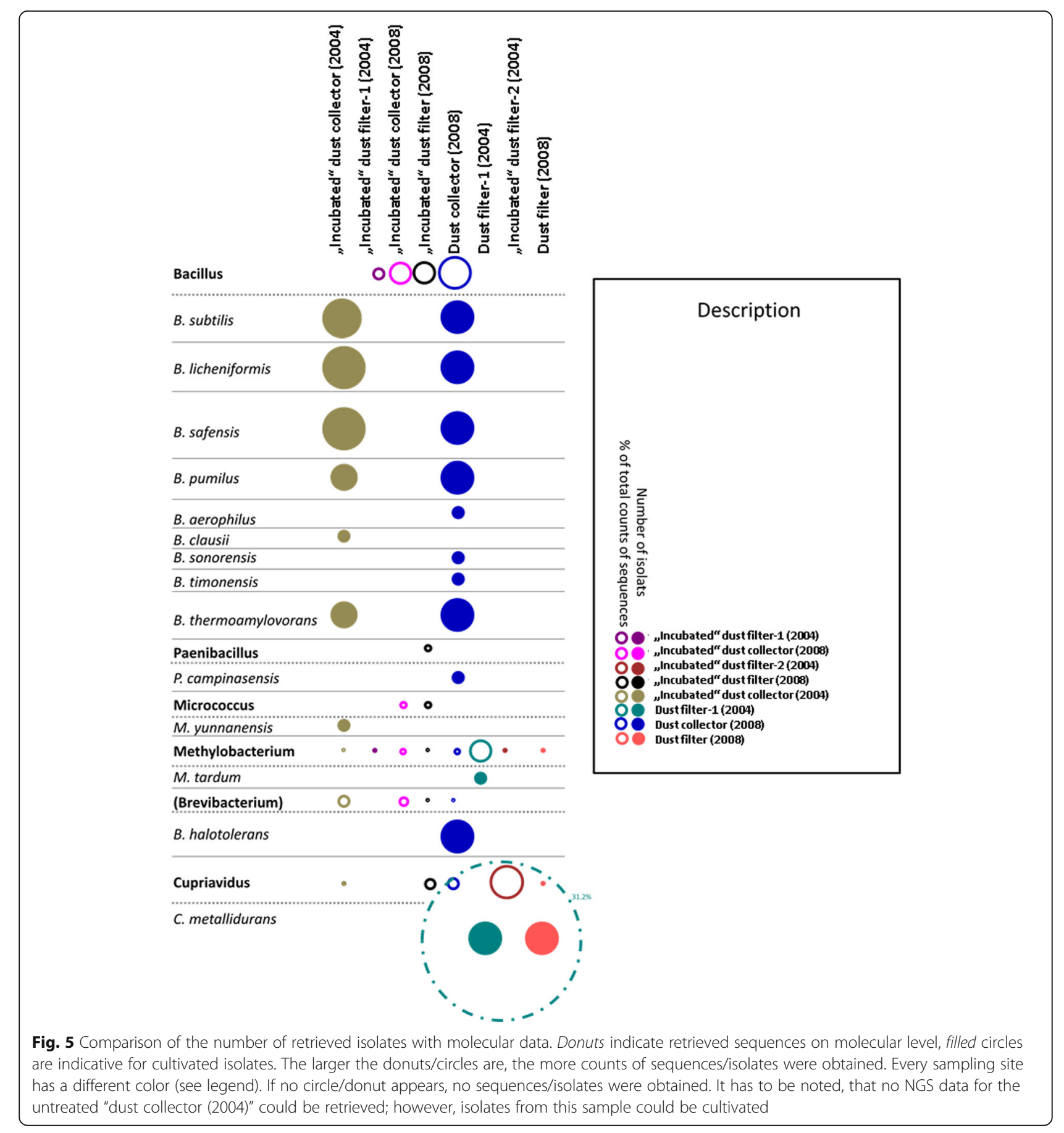


Differences between the microbial communities of archived ISS dust samples (this study) and more freshly retrieved samples [4]

Very recently, a dataset of microbial community composition of comparably fresh dust samples from the US American modules of the ISS has been published (ISS Hepa filter particulares, vacuum cleaner bag components of ISS (ISS Debris); retrieved 2011 and 2012; [4]). These data were retrieved and used for comparison by betadiversity matrices (Bray-Curtis distance (unweighted); see also Additional file 7: Table S6).

We want to emphasize here, that for the sake of comparibility, we exclusively analyzed the forward reads of each study, since in contrast to our study, the reads in the study of Checinska et al. 2015 were not mergeable. However, the PCoA plot in Additional file 4: Figure S4 shows a clear clustering of the US American dust samples (US-ISS; [4]) and the Russian dust samples (RISS, this study), which indicates, despite insufficient possibility of data analysis, a certain dissimilarity of the microbial community in the two different ISS settings. In Table 5, we compared the data derived from Checinska et al. 2015 with our dataset, containing merged and further processed forward and reverse reads. A deeper look into the overall community shows a clear difference in the abundance of the dominant phyla. First, in contrast to the previous study, we were able to detect archaeal sequences, mainly classified as Thaumarchaea. Second, although both studies detected Actinobacteria, Firmicutes, and Proteobacteria as the dominant phyla in all samples, the mean abundance varied. The phylum Actinobacteria was observed to constitute $\sim 64 \%$ of all samples in the US American ISS samples, whereas the older, archived Russian samples only harbored $\sim 24 \%$. In addition, the number of dominant genera was twofold reduced (mean US-ISS: 58 genera, mean RISS (Russian ISS samples): 28 genera). In contrast, the average abundance of Proteobacteria was increased $\sim 8.7$ times (mean values US-ISS: $3.255 \%$, RISS: $27.4 \%$ ); however, the number of genera was higher in US American ISS samples (mean number of genera RISS: 44.125 and mean number of genera US American ISS: 69.78). The amount of classified Firmicutes sequences and genera was comparable in both US American ISS and RISS samples (sequences mean: 25.78 and $28 \%$, respectively, and mean number of genera 79 and 71.5 , respectively).

\section{Prediction of resistance capacities}

Next to the phylogenetic diversity of microorganisms, we also wanted to retrieve information on which genes might be essential to their adaption to this extreme environment. It has to be emphasized that we did not apply a metagenomics approach to assess the entire set of functional genes but used the in silico tool Tax4Fun [30] to predict functional genes derived from our $16 \mathrm{~S}$
rRNA amplicon dataset (universal primer set). In total, we obtained 6558 predicted single genes and 281 pathways (KEGG3 level). We focused on predicted genes/ pathways responsible for antibiotic synthesis/resistance, transporters in general, resistance in general (e.g., resistance against metals or sporulation ability) and compared the individual relative abundances throughout all samples (Fig. 6). First, hierarchical clustering of selected functional genes resulted in two main clusters, consisting of the sample "Dust filter (2008)" with the incubated respective sample and the other samples forming the other cluster. There was no cluster pairing specifically incubated or untreated samples. The gene encoding for the iron complex "outer membrane receptor protein" was predicted to be highly abundant throughout all samples with the exception of the incubated sample "dust filter-2 (2004)." In general, genes encoding for resistances/adaptions were predicted to be equally distributed throughout all samples. These in silico-based predictions are not obligatorily reflecting the actual gene pool and need to be verified experimentally in future work.

\section{Discussion}

In this communication, we retrieved novel information on the resistance capacities of resilient microorganisms derived from archived ISS dust samples. Our work allows deeper insight into the extremotolerant and adapted microbial community therein, revealing the presence of archaeal signatures as well as a robust microbial resistance machinery.

All 85 bacterial isolates survived for a prolonged time period of $8-12$ years in desiccated dust. This implies a desiccation resistance achieved by different strategies, such as spore-forming capability or optimized DNArepair mechanisms (Table 6). The origin of the bacterial isolates remains unknown, but many of them have already been detected in ISS or spacecraft-associated clean rooms or are typical human-associated microorganisms (Table 6.)

It has to be pointed out that the origin of the halophile isolate Salinibacillus is very unclear. It has not been detected on board the ISS or in spacecraft assembly clean rooms before and is also not a typical human-associated bacterium. However, it has recently been detected in human stool, although the authors did suspect an erroneous classification [40].

Nineteen representative ISS isolates were tested for their ability to survive a heat-shock and their susceptibility to 17 clinically relevant antibiotics in vitro. As expected, all spore-forming isolates survived the heat-shock and non-spore-forming isolates did not, except for B. erythrophlei. A few colonies appeared after the heat-shock at $80{ }^{\circ} \mathrm{C}$ for $15 \mathrm{~min}$. It has been reported that 


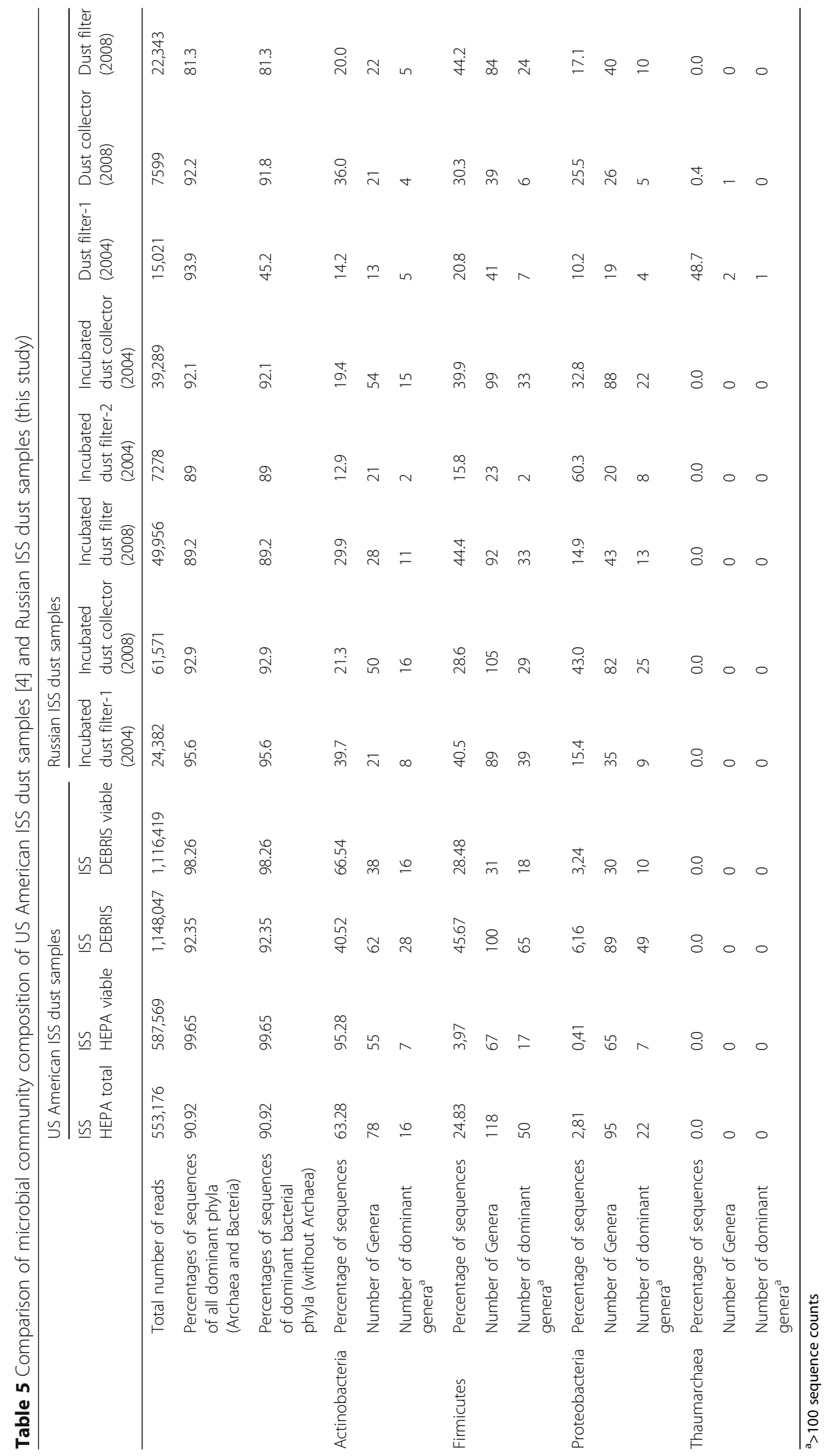




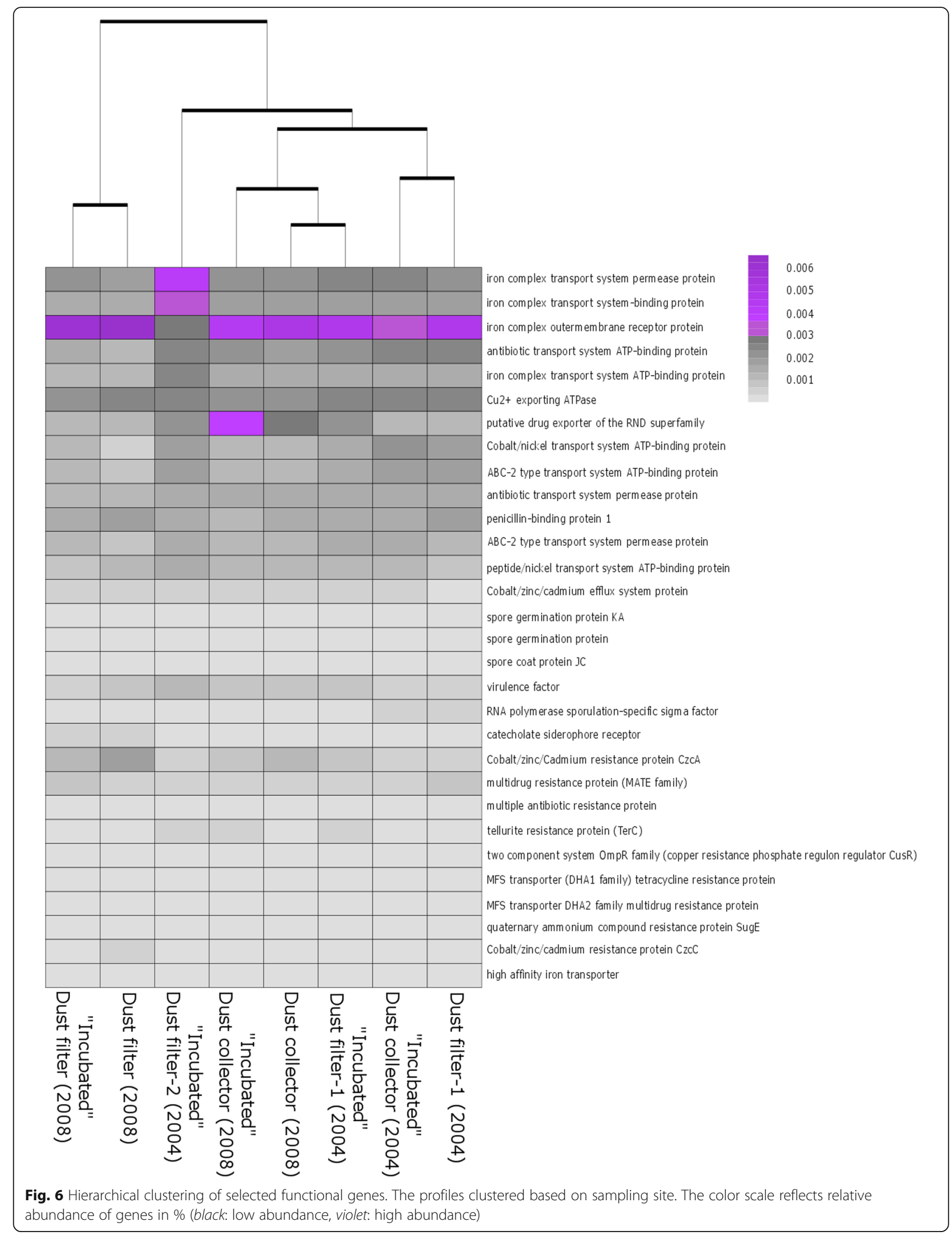


Table 6 Summary of proposed survival strategies of the isolates and their possible origin

\begin{tabular}{llll}
\hline Isolated microbial genus & Possible origin & Proposed survival strategy & References \\
\hline Bacillus & HA, CR, ISS & Endospores & {$[77-83]$} \\
Paenibacillus & CR, ISS & Endospores & {$[78-81]$} \\
Salinibacillus & HA, ENV & Endospores & {$[40,84]$} \\
Micrococcus & HA, CR, ISS, IA & Intrinsic desiccation resistance & {$[81,82,85-88]$} \\
Cupriavidus & CR, ISS & Various DNA-repair mechanisms; adapted to extreme, & {$[78,89]$} \\
Methylobacterium & metal-rich, anthropogenic environments & {$[5,14,20,82,90]$} \\
Bradyrhizobium & CR, ISS, IA & Intrinsic desiccation resistance & {$[5,14,20,81,82,91]$} \\
\hline
\end{tabular}

Legend: $H A$ human-associated; $C R$ reported in spacecraft assembly clean room(s) before; ISS reported in ISS before; ENV environmental; IA indoor air

Bradyrhizobium japonicum, a close relative of B. erythrophlei, possesses multiple small heat-shock proteins that support survival of naturally occurring heat peaks of more than $40{ }^{\circ} \mathrm{C}$ [41]. However, since only a few survivors were found after the $80{ }^{\circ} \mathrm{C}$ treatment, one might assume that such heat-shock proteins, if present in B. erythrophlei, are not a reliable protection at these elevated temperatures.

The same strains were tested for their susceptibility against 17 clinically relevant antibiotics. It should be stressed that none of the isolates obtained was judged to be an opportunistic pathogen, and the antibiotic resistances remain without clinical relevance in this regard. However, the isolates revealed a remarkable pool of antibiotic resistance. Only the isolate M. yunnanensis showed no resistance towards all tested antibiotics. The most resistant isolate which could be evaluated according to the EUCAST standard (see the "Methods" section for more details) was Paenibacillus campinasensis, showing resistance against 8 of the 17 tested antibiotics.

During testing of the cephalosporines cefotaxime and ceftriaxone, we observed a high number of resistant isolates (16/19: cefotaxime and 14/19: ceftriaxone). However, most of the resistant isolates were Bacillus representatives, whereas our few Gram-negative isolates were mostly rated not resistant. Overall, Bacillus species appear to be rather resistant against cefotaxime and ceftriaxone, as reported before for e.g., B. anthracis [42-44].

However, of the two organisms that were tested under adapted conditions (due to no growth on Müller Hinton agar), M. tardum exceeded the non-speciesrelated resistance breakpoints of 11 of the 17 antibiotics, whereas the B. erythrophlei isolate appeared to be even unaffected by almost all of the tested antibiotics except gentamicin. Of course these results have to be evaluated with extreme caution since not all of the EUCAST evaluation criteria could be met. B. erythrophlei was recently isolated from root nodules of Ironwood in south China and subsequently described as a new species [45]. Notably, Bradyrhizobium sp. (Accession number AY599676), now classified as B. erythrophlei, was also recently observed in propidium monoazide treated samples of spacecraft assembly facilities [20]. Bradyrhizobium signatures were reported in high abundance even in intensive care units and hospital biofilms [46, 47]. To date, the impact of Bradyrhizobium species (except for B. enterica) on human health remains elusive, but this genus has obviously a robust strategy for survival under stressful conditions. However, although B. erythroplei is not reported to be pathogenic, it could act as a reservoir for resistance genes on the ISS that might, under selection pressure, be passed on via horizontal gene transfer to infectious microorganisms.

A number of studies have been conducted on the reaction of bacteria to human spaceflight conditions, focusing on the changed pathogenic potential or resistance development [48]. For some microorganisms, an elevated virulence has been found, whereas others remained unaffected [48]. Recently, it has been shown for Staphylococcus species, that even a short-term stay in space can trigger the development of antimicrobial resistance [49]. In addition, decreased susceptibility of microbes to antibiotics under space-flight conditions have been reported [49]. Notably, bacterial infections ocurring during human space-flight on Mir or spaceshuttle have been observed earlier, such as infections of the urinary tract, upper respiratory tract, and subcutaneous tissue, as well as an increased reactivation of latent viral infections due to the deterioration of the astronaut's immune system $[49,50]$.

Of the antibiotics we tested in this study, amoxicillin (without clavulanic acid), ceftriaxone, ciprofloxacin, clindamycin, doxycycline, levofloxacin, sulfamethoxazole/trimethoprim, and moxifloxacin are also ingredients of the ISS medical inventory [51] and can thus be used for treatment of bacterial infections aboard. In our tests (see Table 4), the environmental isolates from ISS were susceptible to amoxicillin (with clavulanic acid), ciprofloxacin, doxycycline, levofloxacin, sulfamethoxazole/ trimethoprim, and moxifloxacin. We confirmed that ceftriaxone is not very effective against Bacillus sp., but it was effective against most non spore-forming isolates. When comparing the measured clindamycin MICs to 
resistance breakpoints defined for other species, 16 of 19 isolates could be rated potentially resistant against clindamycin: For all aerobic microorganisms, for which the clindamycin resistance breakpoint is defined in the EUCAST breakpoint table v6.0, it is " $>0.5 \mu \mathrm{g} / \mathrm{ml}$ " (e.g., Staphylococcus sp. or Corynebacterium sp.). However, due to missing specific resistance breakpoints for nonpathogenic microbial isolates, this finding cannot be used for risk estimations.

The cultivable diversity of our older dust samples (17 bacterial species) was found to be lower than the cultivable diversity of the US American study (26 bacterial species), although a broader variety of cultivation media was used. In both studies, the genus Bacillus was the most prominent genus. However, on species level, no overlap between the isolates of these studies was found, which strongly indicates a difference in the microbial communities of the analyzed samples-either caused by longer storage or an overall difference in the microbiota composition of the Russian modules in 2004/ 2008 and of the US American modules in 2008-2012 (US American HEPA filter was installed from 2008 to 2011 and US American vacuum cleaner samples were taken 2012 [4]). Because of the use of nystatin in our study, we isolated only one eukaryotic isolate, $U$. botrytis, retrieved from medium with a $\mathrm{pH}$ of 9 . U. botrytis was also not among the ten different fungi isolated by Checinska et al. 2015 (Additional file 3: Table S3).

Besides the analysis of the isolates, we carried out a comprehensive sequencing study to shed light onto the microbial diversity that was present $8-12$ years ago in the Russian ISS segment.

Notably, PMA treatment did not result in positive amplification of $16 \mathrm{~S}$ rRNA genes, although cultivation efforts confirmed the presence of viable cells. Either those were present only in very low numbers, so that the PMA treatment resulted in DNA below detection limit, and/or the microbes were present as hardy spores. The latter observation is in accordance with the sequencing results showing a high proportion of Bacilli $(17.4 \%)$ and Clostridia (13.7\%), whose spores require a harsh DNA extraction method [52].

In order to increase the amount of available DNA in the samples, and possibly also to trigger spore germination, we incubated the samples in warm LB medium before DNA extraction. Although the shift of the microbial community caused by the incubation was found to be substantial, we were able to retrieve enough DNA for a positive amplification of $16 \mathrm{~S}$ rRNA genes in all samples. Without incubation, only three out of five samples gave a positive signal.

Besides spore-formers, our dataset revealed a high presence of signatures belonging to human-associated bacteria, including Pseudomonas [53], Acinetobacter
[54], Sphingomonas [55], and Corynebacterium [56], throughout all samples. Most of these microbes have been detected on the human skin (such as Corynebacterium and Staphylococcus) and in the human gut (such as the strictly anaerobic Faecalibacterium). These findings confirm that the indoor airborne microbial community is derived directly from the astronauts' presence as discussed in other studies $[4,57,58]$.

We also found signatures of other strictly anaerobic genera, such as Anaerococcus and Anaerostipes, which can, however, tolerate oxygen when dormant. An intensive study of all taxa revealed a high proportion of extremotolerant microorganisms such as (i) sporeforming bacilli, with known resistance against radiation, pressure, desiccation, and space and Marssimulation conditions [59-63] (and references therein), (ii) signatures of Rhodococcus, known for high resistance against desiccation and ultraviolet radiation [64], and (iii) members of Cyanobacteria, which are considered to be highly resistant against extreme conditions [65] (and references therein). The presence of extremotolerant microorganisms is also reflected in the predicted metabolic capacities. A various range of predicted genes encoding features which help organisms to withstand extreme conditions such as the twocomponent-system, several transporters, iron acquisition, and antibiotic resistance could be detected and were distributed equally throughout all samples.

In order to gain insight into the overall microbial community of the ISS, we compared the microbial community of the US segment [4] and the Russian segment (our study) by performing a joint data analysis, using NGS raw reads from both studies, processed by DADA2. We observed a high dissimilarity in the microbial composition between both segments, potentially caused by the different location, sampling time frame or methods used to gather the data. However, in the US segment, the microbial community was also dominated by human-associated microorganisms and the same core taxa on phylum level (Actinobacteria, Firmicutes, and Proteobacteria), although with a different relative abundance. It should be mentioned that a deeper comparison of both settings was not possible, due to the different primers used in the US segment study, as well as the short reads obtained ( 130 bp is considered borderline for proper classification; paired reads could not be stitched [4]).

The most striking difference found during our comparison of already available data and that from our new study was the presence of archaeal signatures in the Russian samples. Overall, the presence of Archaea on the ISS has not been reported before, or previous attempts to detect them were negative $[4,5]$. Archaea are generally known to be widely distributed in extreme 
environments, and are specifically well-adapted to biotopes with energy constraints. In our samples, we mainly found Nitrososphaera signatures, belonging to a group of chemolithoauthotrophic, ammonia-oxidizing archaea, distributed in soil and hot springs, but also abundant on human skin [16, 66]. Interestingly, in spite of known mismatches in the used primers [16], Nitrososphaera was also detected with universal primers, indicating a high abundance in the dust samples.

Signatures of human-associated Methanobrevibacter could also be observed. Methanobrevibacter species are described as anaerobic, human gut commensals [67]. Notably, the (rare) presence of Woesearchaeota signatures can also be reported. Their detection has been occasionally described in samples from soils and aquatic environments $[68,69]$. Castelle et al. analyzed their genomic potential, revealing a small genome size and limited metabolic capacities, which suggests that these Archaea might have a symbiotic or parastic lifestyle [70]. Although the detection of archaeal $16 \mathrm{~S}$ rRNA gene signatures cannot inform on the role and activity of these microbes yet, we can state that the International Space Station is/was indeed populated by all three domains of life.

\section{Conclusions}

The ISS dust microbiome analyzed in this study contained living, hardy microorganisms and showed the presence of archaeal signatures. Numerous resistance capabilities towards environmental stresses were either predicted on a molecular level or shown by retrieved isolates. It should be stressed, that, although these findings raise many questions and require discussion, the International Space Station is and has always been a safe workplace [71] and no severe infections or disease outbreaks have been reported thus far. The specific resistance capacities of our nonpathogenic ISS isolates against desiccation, heat-shock, and some antibiotic compounds refer to samples that have been collected around a decade ago, and the findings need to be reconfirmed with novel microbial isolates. Nevertheless, it remains without doubt that microorganisms on the ISS experience selective pressures and that a number of microbes adapt to these stresses. Our findings and those of previous publications in this regard can now be considered for the planning of future, crewed long-term spaceflights, but also for potential habitats on the moon or other planetary bodies.

\section{Additional files}

Additional file 1: Table S1. DADA2 output including negative controls (universal primer set); Highlighted RSVs were also found in the negative controls "RISS-LB-incubation-NC" and "RISS-protocol-NC" and were therefore removed from the dataset for further analysis. (XLSX $212 \mathrm{~kb}$ )
Additional file 2: Table S2. DADA2 output including negative control (archaeal primer set); After chimera filtering (see the "Bioinformatical analysis and data processing" section), no reads remained in the negative control ("RISSArch-protocol-NC"). (XLSX 8 kb)

Additional file 3: Table S3. Comparison of isolates from this study and Checinska et al. (2015). (DOCX $15 \mathrm{~kb}$ )

Additional file 4: Supplementary Figures. Figure S1 A+B. Resistance tests: minimal inhibitory concentration for 19 isolates as measured for 12 different antibiotics up to $256 \mu \mathrm{g} / \mathrm{ml}$ (A) or $32 \mu \mathrm{g} / \mathrm{l}$ (B). Horizontal lines show the non-species related breakpoints defined by EUCAST (Version 6.0, 2016). Above upper line: organism is resistant; below lower line: organism is sensitive; Y-axis shows the logarithmic concentration of the antibiotics as indicated on the Etest ${ }^{\oplus}$ reagent strips. Figure S2. Diversity of Archaea signatures in ISS samples. Displayed are observed taxa (richness), Shannon Index and InvSimpson Index. Figure S3. Differentially abundant genera in untreated and incubated samples. Figure S4. PcoA plot (unweighted Bray-Curtis distance) of US-ISS samples (US-ISS) and Russian ISS (RISS) samples. It has to be emphasized that only forward reads of both studies were processed here. Based on this approach, a clear, distinct clustering of Russian ISS samples and US-ISS samples is observed, which indicates dissimilarity in the microbial composition. (PPTX $477 \mathrm{~kb}$ )

Additional file 5: Table S4. DADA2 output (archaeal primer set; negative controls removed). (XLSX $8 \mathrm{~kb}$ )

Additional file 6: Table S5. DADA2 output (universal primer set; negative controls removed). (XLSX $192 \mathrm{~kb}$ )

Additional file 7: Table S6. Comparison of the ISS microbial community of archived dust samples (this study; "Dust filter and "Dust collector" samples) and freshly retrieved samples (Checinska et al. 2015; "HEPA-debris" and "vacuum-cleaner-bag-debris" samples). (XLSX 60 kb)

\section{Acknowledgements}

The authors thank D. N. Srienz, C. Strempfl, and S. K. Obersteiner for their technical assistance while performing and evaluating the antimicrobial susceptibility tests. The authors also thank A. Stevens, C. Ludon, K. Koskinen, and M. Pausan for critically reading the manuscript and G. Berg, M. Grube and R. Wirth for their fruitful discussion.

The ARBEX project is currently being prepared for flight by the European Space Agency (OpNom "Extremophiles"). The authors thank J. Hatton, R. Demets, F. Wyss, M. Herová, B. Rattenbacher, and L. Zuijderduijn for the discussion and support.

\section{Funding}

The ARBEX project received funding from of the Austrian "Forschungsförderungsgesellschaft" FFG (Project number: 847977). MM is trained within the frame of the PhD Program Molecular Medicine of the Medical University of Graz. The project is supported by BioTechMed Graz.

\section{Availability of data and materials}

The datasets generated and analyzed during this study are available in the European Nucleotide Archive (http://www.ebi.ac.uk/ena); the Sanger sequences are available via accession numbers LT617056-LT617090. Ilumina MiSeq reads are accessible via study accession number: PRJEB14961.

\section{Authors' contributions}

MM and AP contributed equally to this study. MM planned and executed the laboratory work, evaluated the data, and wrote the paper. AP performed the bioinformatics and biostatistics and wrote the paper. TAA, AA, and TN provided and pre-processed the samples and provided the metadata. LW performed experiments and provided input for writing the paper. RK provided critical input for execution and evaluation of the antimicrobial susceptibility tests. CME, principal investigator of the ARBEX project, initiated, planned the study, evaluated experiments, performed bioinformatics, and wrote the paper. All authors read and approved the final manuscript.

\section{Competing interests}

The authors declare that they have no competing interests.

Consent for publication

Not applicable. 


\section{Ethics approval and consent to participate}

Not applicable.

\begin{abstract}
Author details
${ }^{1}$ Department for Internal Medicine, Section of Infectious Diseases and Tropical Medicine, Medical University of Graz, Auenbruggerplatz 15, 8036 Graz, Austria. ${ }^{2}$ Department for Microbiology, University of Regensburg, Universitätsstr. 31, 93053 Regensburg, Germany. 'Lomonosov Moscow State University, Leninskie Gory, 119991 Moscow, Russia. ${ }^{4}$ BioTechMed Graz, Krenngasse 37, 8010 Graz, Austria.
\end{abstract}

Received: 17 August 2016 Accepted: 3 December 2016 Published online: 20 December 2016

\section{References}

1. Mora M, Mahnert A, Koskinen K, Pausan MR, Oberauner-Wappis L, Krause R, et al. Microorganisms in confined habitats: microbial monitoring and control of the International Space Station, cleanrooms, operating rooms and intensive care units. Front. Microbiol. 2016; 7:1573. Available from: http://dx. doi.org/10.3389/fmicb.2016.01573. Accessed 7 Dec 2016.

2. Moissl-Eichinger C, Cockell C, Rettberg P. Venturing into new realms? Microorganisms in space. FEMS Microbiol Rev. 2016;40(5):722-37.

3. Coil DA, Neches RY, Lang JM, Brown WE, Severance M, Cavalier DD, et al. Growth of 48 built environment bacterial isolates on board the International Space Station (ISS). PeerJ. 2016;4:e1842.

4. Checinska A, Probst AJ, Vaishampayan P, White JR, Kumar D, Stepanov VG, et al. Microbiomes of the dust particles collected from the International Space Station and Spacecraft Assembly Facilities. Microbiome. 2015;3:1-18.

5. Venkateswaran K, Vaishampayan P, Cisneros J, Pierson DL, Rogers SO, Perry J. International Space Station environmental microbiome- microbial inventories of ISS filter debris. Appl Microbiol Biotechnol. 2014: 98.

6. Alekhova TA, Zakharchuk LM, Tatarinova NY, Kadnikov W, Mardanov AV, Ravin NV, et al. Diversity of bacteria of the genus Bacillus on board of international space station. Dokl Biochem Biophys. 2015;465:347-50.

7. Novikova ND, Polikarpov NA, Poddubko S V, Deshevaya EA. The results of microbiological research of environmental microflora of orbital station Mir. SAE Technical Paper; 2001

8. Novikova ND. Review of the knowledge of microbial contamination of the Russian manned spacecraft. Microb Ecol. 2004:47:127-32.

9. Alekhova TA, Aleksandrova AA, Novozhilova TY, Lysak LV, Zagustina NA, Bezborodov AM. Monitoring of microbial degraders in manned space stations. Appl Biochem Microbiol. 2005;41:382-9.

10. NRC. Committee for the Decadal Survey on Biological Physical Sciences in Space: recapturing a future for space exploration: life and physical sciences research for a new era. Washington, DC: The National Academies Press; 2011.

11. Qian J, Hospodsky D, Yamamoto N, Nazaroff WW, Peccia J. Size-resolved emission rates of airborne bacteria and fungi in an occupied classroom. Indoor Air. 2012:22:339-51.

12. Grice EA, Kong HH, Conlan S, Deming CB, Davis J, Young AC, et al. Topographical and temporal diversity of the human skin microbiome. Science. 2009;324:1190-2.

13. Ott CM, Crabbé A, Wilson JW, Barrila J, Castro SL, Nickerson CA. Microbial stress: spaceflight-induced alterations in microbial virulence and infectious disease risks for the crew. Berlin Heidelberg: Stress Challenges Immun. Sp. Springer; 2012. p. 203-25.

14. Bruce RJ, Ott CM, Skuratov VM, Pierson DL. Microbial surveillance of potable water sources of the International Space Station. SAE Trans Soc Automot Eng. 2005;114:283-92.

15. Moissl-Eichinger C. Archaea in artificial environments: their presence in global spacecraft clean rooms and impact on planetary protection. ISME J. 2011:5:209-19. doi: 10.1038/ismej.2010.124.

16. Probst AJ, Auerbach AK, Moissl-Eichinger C. Archaea on human skin. PLoS One. 2013;8:e65388.

17. Gaci N, Borrel G, Tottey W, OToole PW, Brugère J-F. Archaea and the human gut: new beginning of an old story. World J Gastroenterol. 2014;20:16062.

18. Stieglmeier M, Rettberg P, Barczyk S, Bohmeier M, Pukall R, Wirth R, et al. Abundance and diversity of microbial inhabitants in European spacecraftassociated clean rooms. Astrobiology. 2012;12:572-85.

19. Kim O-S, Cho Y-J, Lee $\mathrm{K}$, Yoon S-H, Kim M, Na H, et al. Introducing EzTaxone: a prokaryotic $16 S$ rRNA gene sequence database with phylotypes that represent uncultured species. Int. J. Syst. Evol. Microbiol. Microbiology Society; 2012;62:716-21

20. Vaishampayan P, Probst AJ, La Duc MT, Bargoma E, Benardini JN, Andersen GL, et al. New perspectives on viable microbial communities in low-biomass cleanroom environments. ISME J. 2013;7:312-24.

21. Caporaso JG, Lauber CL, Walters WA, Berg-Lyons D, Huntley J, Fierer N, et al. Ultra-high-throughput microbial community analysis on the Illumina HiSeq and MiSeq platforms. ISME J. 2012;6:1621-4.

22. Raskin L, Stromley JM, Rittmann BE, Stahl DA. Group-specific 16S rRNA hybridization probes to describe natural communities of methanogens. Appl Environ Microbiol. 1994;60:1232-40.

23. Stahl D A, Amann R. Development and application of nucleic acid probes. In: Stackebrandt E, Goodfellow M, editors. Nucleic acid techniques in bacterial systematics. New York: John Wiley \& Sons, Inc.; 1991. pp. 205-248.

24. Klindworth A, Pruesse E, Schweer T, Peplies J, Quast C, Horn M, et al. Evaluation of general 165 ribosomal RNA gene PCR primers for classical and next-generation sequencing-based diversity studies. Nucleic Acids Res. 2012; $\mathrm{kks} 808$.

25. Eucast. PK/PD (Non-species related) breakpoints [Internet]. [cited 2016 Jul 1]. Available from: http://www.eucast.org/fileadmin/src/media/PDFs/EUCAST_ files/Breakpoint_tables/v_6.0_Breakpoint_table.pdf

26. ECSS. Microbial examination of flight hardware and cleanrooms ECSS-Q-ST70-55C. 2008;

27. Callahan BJ, McMurdie PJ, Rosen MJ, Han AW, Johnson AJA, Holmes SP. DADA2: high-resolution sample inference from Illumina amplicon data. Nat Methods. 2016;13:581-3.

28. McMurdie PJ, Holmes S. phyloseq: an R package for reproducible interactive analysis and graphics of microbiome census data. PLoS One. 2013;8:e61217.

29. Callahan BJ, Sankaran K, Fukuyama JA, McMurdie PJ, Holmes SP. Bioconductor workflow for microbiome data analysis: from raw reads to community analyses. F1000Research. 2016;5.

30. Aßhauer KP, Wemheuer B, Daniel R, Meinicke P. Tax4Fun: predicting functional profiles from metagenomic 16S rRNA data. Bioinformatics. 2015;31:2882-4.

31. Parks DH, Tyson GW, Hugenholtz P, Beiko RG. STAMP: statistical analysis of taxonomic and functional profiles. Bioinformatics. 2014;30:3123-4.

32. Caporaso JG, Kuczynski J, Stombaugh J, Bittinger K, Bushman FD, Costello EK, et al. QIIME allows analysis of high-throughput community sequencing data. Nat Methods. 2010;7:335-6.

33. Schloss PD, Westcott SL, Ryabin T, Hall JR, Hartmann M, Hollister EB, et al. Introducing mothur: open-source, platform-independent, communitysupported software for describing and comparing microbial communities. Appl Environ Microbiol. 2009;75:7537-41.

34. Tamura K, Stecher G, Peterson D, Filipski A, Kumar S. MEGA6: molecular evolutionary genetics analysis version 6.0. Mol. Biol. Evol. 2013;mst197.

35. Letunic I, Bork P. Interactive Tree Of Life (iTOL): an online tool for phylogenetic tree display and annotation. Bioinformatics. 2007;23:127-8

36. Heberle $H$, Meirelles GV, da Silva FR, Telles GP, Minghim R. InteractiVenn: a web-based tool for the analysis of sets through Venn diagrams. BMC Bioinformatics. 2015:16:1

37. Leclercq R, Cantón R, Brown DFJ, Giske CG, Heisig P, Macgowan AP, et al. EUCAST expert rules in antimicrobial susceptibility testing. Clin Microbiol Infect. 2013;19:141-60.

38. Nocker A, Sossa-Fernandez P, Burr MD, Camper AK. Use of propidium monoazide for live/dead distinction in microbial ecology. Appl Env Microbiol. 2007:73

39. Quast C, Pruesse E, Yilmaz P, Gerken J, Schweer T, Yarza P, et al. The SILVA ribosomal RNA gene database project: improved data processing and webbased tools. Nucleic Acids Res. 2013;41:D590-6.

40. Endesfelder $D$, Engel M, Davis-Richardson AG, Ardissone AN, Achenbach $P$ Hummel S, et al. Towards a functional hypothesis relating anti-islet cell autoimmunity to the dietary impact on microbial communities and butyrate production. Microbiome. 2016;4:1.

41. Munchbach M, Nocker A, Narberhaus F. Multiple small heat shock proteins in rhizobia. J Bacteriol. 1999:181:83-90.

42. Doĝanay M, Aydin N. Antimicrobial susceptibility of Bacillus anthracis. Scand J Infect Dis. 1991:23:333-5.

43. Mohammed MJ, Marston CK, Popovic T, Weyant RS, Tenover FC. Antimicrobial susceptibility testing of Bacillus anthracis: comparison of results obtained by using the National Committee for Clinical Laboratory Standards broth microdilution reference and Etest agar gradient diffusion methods. J Clin Microbiol Am Soc Microbiol. 2002;40:1902-7. 
44. Turnbull PCB, Sirianni NM, LeBron Cl, Samaan MN, Sutton FN, Reyes AE, et al. MICs of selected antibiotics for Bacillus anthracis, Bacillus cereus, Bacillus thuringiensis, and Bacillus mycoides from a range of clinical and environmental sources as determined by the Etest. J Clin Microbiol Am Soc Microbiol. 2004;42:3626-34.

45. Yao Y, Sui XH, Zhang XX, Wang ET, Chen WX. Bradyrhizobium erythrophlei sp. nov. and Bradyrhizobium ferriligni sp. nov., isolated from effective nodules of Erythrophleum fordii. Int J Syst Evol Microbiol. 2015;65:1831-7.

46. Oberauner L, Zachow C, Lackner S, Högenauer C, Smolle K-H, Berg G. The ignored diversity: complex bacterial communities in intensive care units revealed by 165 pyrosequencing. Sci Rep. 2013;3:1413.

47. Soto-Giron MJ, Rodriguez-R LM, Luo C, Elk M, Ryu H, Hoelle J, et al. Biofilms on hospital shower hoses: characterization and implications for nosocomial infections. Appl Environ Microbiol. 2016;82:2872-83.

48. Rosenzweig JA, Ahmed S, Eunson J, Chopra AK. Low-shear force associated with modeled microgravity and spaceflight does not similarly impact the virulence of notable bacterial pathogens. Appl Microbiol Biotechnol. 2014; 98:8797-807.

49. Fajardo-Cavazos P, Nicholson WL. Cultivation of Staphylococcus epidermidis in the human spaceflight environment leads to alterations in the frequency and spectrum of spontaneous rifampicin-resistance mutations in the rpoB gene. Front Microbiol . 2016;7:1-10.

50. Mehta SK, Laudenslager ML, Stowe RP, Crucian BE, Sams CF, Pierson DL. Multiple latent viruses reactivate in astronauts during Space Shuttle missions. Brain Behav Immun. 2014:41:210-7.

51. NASA. National Aeronautics and Space Administration (NASA) Emergency Medical Procedures Manual for the International Space Station (ISS) [partial], 2016. governmentattic.org. 2016.

52. Kuske CR, Banton KL, Adorada DL, Stark PC, Hill KK, Jackson PJ. Small-scale DNA sample preparation method for field PCR detection of microbial cells and spores in soil. Appl Environ Microbiol Am Soc Microbiol. 1998;64:2463-72.

53. Trautmann M, Lepper PM, Haller M. Ecology of Pseudomonas aeruginosa in the intensive care unit and the evolving role of water outlets as a reservoir of the organism. Am J Infect Control. 2005;33:S41-9.

54. Hartzell JD, Kim AS, Kortepeter MG, Moran KA. Acinetobacter pneumonia: a review. Medscape Gen. Med. WebMD/Medscape Health Network; 2007;9:4.

55. White DC, Sutton SD, Ringelberg DB. The genus Sphingomonas: physiology and ecology. Curr Opin Biotechnol. 1996;7:301-6.

56. Soriano F, Zapardiel J, Nieto E. Antimicrobial susceptibilities of Corynebacterium species and other non-spore-forming gram-positive bacilli to 18 antimicrobial agents. Antimicrob Agents Chemother. 1995;39:208-14.

57. Hospodsky D, Qian J, Nazaroff WW, Yamamoto N, Bibby K, Rismani-Yazdi H, et al. Human occupancy as a source of indoor airborne bacteria. PLoS One. 2012;7:e34867.

58. Adams Rl, Bhangar S, Pasut W, Arens EA, Taylor JW, Lindow SE, et al. Chamber bioaerosol study: outdoor air and human occupants as sources of indoor airborne microbes. PLoS One. 2015;10:e0128022.

59. Tauscher C, Schuerger AC, Nicholson WL. Survival and germinability of Bacillus subtilis spores exposed to simulated Mars solar radiation: implications for life detection and planetary protection. Astrobiology. 2006; 6:592-605.

60. Dose K, Klein A. Response of Bacillus subtilis spores to dehydration and UV irradiation at extremely low temperatures. Orig Life Evol Biosph. 1996;26:47-59.

61. Vaishampayan PA, Rabbow E, Horneck G, Venkateswaran KJ. Survival of Bacillus pumilus spores for a prolonged period of time in real space conditions. Astrobiology. 2012;12:487-97.

62. Horneck G, Moeller R, Cadet J, Douki T, Mancinelli RL, Nicholson WL, et al, Resistance of bacterial endospores to outer space for planetary protection purposes - experiment PROTECT of the EXPOSE-E mission. Astrobiology. 2012;12:445-56

63. Setlow P. Spores of Bacillus subtilis: their resistance to and killing by radiation, heat and chemicals. J Appl Microbiol. 2006;101:514-25.

64. LeBlanc JG, Milani C, de Giori GS, Sesma F, van Sinderen D, Ventura M. Bacteria as vitamin suppliers to their host: a gut microbiota perspective. Curr Opin Biotechnol. 2013;24:160-8.

65. Rampelotto PH. Resistance of microorganisms to extreme environmental conditions and its contribution to astrobiology. Sustainability. 2010;2: 1602-23.

66. Hatzenpichler R, Lebedeva EV, Spieck E, Stoecker K, Richter A, Daims H, et al. A moderately thermophilic ammonia-oxidizing crenarchaeote from a hot spring. Proc Natl Acad Sci. 2008;105:2134-9.
67. Miller TL, Wolin MJ, de Macario EC, Macario AJ. Isolation of Methanobrevibacter smithii from human feces. Appl Environ Microbiol. 1982;43:227-32.

68. Dojka MA, Hugenholtz P, Haack SK, Pace NR. Microbial diversity in a hydrocarbon-and chlorinated-solvent-contaminated aquifer undergoing intrinsic bioremediation. Appl Environ Microbiol. 1998;64:3869-77.

69. Großkopf R, Janssen PH, Liesack W. Diversity and structure of the methanogenic community in anoxic rice paddy soil microcosms as examined by cultivation and direct 165 rRNA gene sequence retrieval. Appl Environ Microbiol. 1998;64:960-9.

70. Castelle CJ, Wrighton KC, Thomas BC, Hug LA, Brown CT, Wilkins MJ, et al. Genomic expansion of domain archaea highlights roles for organisms from new phyla in anaerobic carbon cycling. Curr Biol. 2015;25:690-701.

71. Van Houdt R, Mijnendonckx K, Leys N. Microbial contamination monitoring and control during human space missions. Planet Space Sci. 2012;60:115-20.

72. Patolel M, Phadnis N. The "K"selected oligophilic bacteria: a key to uncultured diversity? Curr. Sci. 2000;78(12):1535-42. ISSN 0011-3891.

73. Balch WE, Fox GE, Magrum LJ, Woese CR, Wolfe RS. Methanogens: reevaluation of a unique biological group. Microbiol Rev. 1979;43:260.

74. Stieglmeier M, Wirth R, Kminek G, Moissl-Eichinger C. Cultivation of anaerobic and facultatively anaerobic bacteria from spacecraft-associated clean rooms. Appl Environ Microbiol. 2009;75:3484-91.

75. Antibiotics Info [Internet]. [cited 2016 Jul 1]. Available from: http://www. antibiotics-info.org/

76. Grayson ML. Kucers' the use of antibiotics: a clinical review of antibacterial, antifungal, antiparasitic, and antiviral drugs. Hodder Arnold London United Kingdom; 2010

77. Hong HA, To E, Fakhry S, Baccigalupi L, Ricca E, Cutting SM. Defining the natural habitat of Bacillus spore-formers. Res Microbiol. 2009;160:375-9.

78. Moissl-Eichinger C, Pukall R, Probst AJ, Stieglmeier M, Schwendner P, Mora M, et al. Lessons learned from the microbial analysis of the Herschel spacecraft during assembly, integration, and test operations. Astrobiology. 2013;13:1125-39.

79. Ghosh S, Osman S, Vaishampayan P, Venkateswaran K. Recurrent isolation of extremotolerant bacteria from the clean room where Phoenix spacecraft components were assembled. Astrobiology. 2010;10:325-35.

80. La Duc MT, Dekas A, Osman S, Moissl C, Newcombe D, Venkateswaran K. Isolation and characterization of bacteria capable of tolerating the extreme conditions of clean room environments. Appl Environ Microbiol. 2007;73: 2600-11.

81. Castro AV, Thrasher NA, Healy M, Ott MC, Pierson LD. Microbial characterization during the early habitation of the International Space Station. Microb Ecol. 2004;47:119-26.

82. Novikova N, Boever P, Poddubko S, Deshevaya E, Polikarpov N, Rakova N. Survey of environmental biocontamination on board the International Space Station. Res Microbiol. 2006;157:5-12.

83. Nicholson WL, Munakata N, Horneck G, Melosh HJ, Setlow P. Resistance of Bacillus endospores to extreme terrestrial and extraterrestrial environments. Microbiol Mol Biol Rev. 2000;64:548-72.

84. Ren P-G, Zhou P-J. Salinibacillus aidingensis gen. nov., sp. nov. and Salinibacillus kushneri sp. nov., moderately halophilic bacteria isolated from a neutral saline lake in Xin-Jiang, China. Int J Syst Evol Microbiol. 2005;55:949-53.

85. Grice EA, Segre JA. The skin microbiome. Nat Rev Microbiol. 2011;9:244-53.

86. Moissl-Eichinger C, Rettberg P, Pukall R. The first collection of spacecraftassociated microorganisms: a public source for extremotolerant microorganisms from spacecraft assembly clean rooms. Astrobiology. 2012; 12:1024-34.

87. Kooken JM, Fox KF, Fox A. Characterization of Micrococcus strains isolated from indoor air. Mol Cell Probes. 2012;26:1-5.

88. Bonetta S, Bonetta S, Mosso S, Sampò S, Carraro E. Assessment of microbiological indoor air quality in an Italian office building equipped with an HVAC system. Environ Monit Assess. 2010;161:473-83.

89. Monsieurs P, Mijnendonckx K, Provoost A, Venkateswaran K, Ott CM, Leys $N$, et al. Genome sequences of Cupriavidus metallidurans strains NA1, NA4, and NE12, isolated from space equipment. Genome Announc. 2014;2:e00719-14.

90. Hugenholtz P, Cunningham MA, Hendrikz JK, Fuerst JA. Desiccation resistance of bacteria isolated from an air-handling system biofilm determined using a simple quantitative membrane filter method. Lett Appl Microbiol. 1995;21:41-6.

91. Cytryn EJ, Sangurdekar DP, Streeter JG, Franck WL, Chang W, Stacey G, et al. Transcriptional and physiological responses of Bradyrhizobium japonicum to desiccation-induced stress. J Bacteriol. 2007;189:6751-62. 